\title{
1 The relevance of functional amino acids to support the health of growing pigs
}

\section{Text}

Nathalie Le Floc'h ${ }^{\mathrm{a}}$, Anna Wessels ${ }^{\mathrm{b}}$, Etienne Corrent ${ }^{\mathrm{c}}$, Guoyao Wu $^{\mathrm{d}}$, Paolo Bosi ${ }^{\mathrm{e}, *}$

a PEGASE, INRA, Agrocampus Ouest, 35590, Saint-Gilles, France

${ }^{b}$ Department of Animal and Food Science, Faculty for Veterinary Science, Autonomous University of Barcelona, 08193 Bellaterra, Spain

${ }^{c}$ Ajinomoto Eurolysine S.A.S., 75017 Paris, France

${ }^{d}$ Department of Animal Science and Center for Animal Genomics, Texas A\&M University, College Station, TX 77843, USA

${ }^{e}$ Department of Agricultural and Food Sciences, University of Bologna, 20127 Bologna, Italy

*Corresponding author.E-mail address: paolo.bosi@unibo.it (P. Bosi).

Abstract

On commercial farms, young growing pigs are frequently affected by health problems from multifactorial origins (e.g. environmental changes, biosecurity, management, and feed) that result in inflammation and activation of body defenses. Inflammation states alter animal metabolism in such a way that nutrients (particularly amino acids) are diverted from the use for growth towards the production of defense-related proteins and low-molecular-weight compounds (e.g., nitric oxide, $\mathrm{H}_{2} \mathrm{~S}$, and glutathione) for supporting the activity of rapidly dividing cells such as immune cells and enterocytes. Furthermore, amino acids may act specifically as signaling molecules to regulate metabolic pathways during inflammation. Thus, new knowledge on the specific role and metabolism of each amino acid is needed to refine nutritional recommendations for pigs of different phenotypes and genotypes, with the objective of maintaining animal health and performance under sub-optimal rearing conditions. This paper aims at summarizing recent advances in research on the functional roles of amino acids related to swine health. Specifically, the review highlights current knowledge on the impact of inflammation on the intake and metabolism of amino acids; 
syntheses of defense molecules and in the regulation of immune response. Practical implications for feeding strategies adapted to various health conditions of growing pigs are also discussed along with our general perspectives on related research.

Keywords: Amino acid, Gut barrier, Inflammation, Metabolism, Nutrient requirements, Pig

Abbreviations: AAs, amino acids; APP, acute-phase protein; Arg, arginine, Asn, asparagine; Asp, aspartate; $\mathrm{CP}$, crude protein; Cys, cysteine; ETEC, enterotoxigenic Escherichia coli K88; Gln, glutamine; Glu, glutamate; Gly, glycine; GSH, glutathione; His, histidine, Ig, immunoglobulin; Leu, leucine; Lys, lysine; Met, methionine; NO, nitric oxide; Pro, proline; Ser, serine; Thr, threonine; TJ, tight junction; Trp, tryptophan, Val, valine; ZO, zonula occludens

\section{Introduction}

The production performance of pigs is highly variable within a farm and among farms, and their health status is one of the factors explaining such differences (Rojo-Gimeno et al., 2016). As many diseases have multifactorial origins, feeding strategies should be considered to support optimal animal growth and health. To this end, the impact of health on the nutritional and metabolic states of pigs needs to be determined to better adjust feeding programs.

Among the dietary nutrients whose intake, digestion, absorption and metabolism by the pig are greatly impacted during stress and inflammation, amino acids (AAs) are good candidates for feeding adjustments because they have key roles in animal metabolism $(\mathrm{Wu}, 2013)$. As sanitary or stress challenges may cause deviation from the homeostasis state in pigs, these factors also affect diverse processes involving AAs and proteins. For example, the occurrence of runt pigs is associated with low concentrations of essential and nonessential AAs in plasma during both the nursery and finishing periods (He et al., 2016). During the recovery after a period of poor health, the utilization of sulfur AAs, threonine (Thr) and tryptophan (Trp) for growth is reduced when growing pigs are fed a diet with a low content of these AAs because of competition between skeletal muscle and the immune system (Kampman-van de Hoek et al., 2016). Although reports on AA requirements for pigs under suboptimal sanitary conditions exist (Litvak et al., 2013; Capozzalo et al., 
2017; Jayaraman et al., 2017), there is a paucity of information about the potential sources of variation in dietary AA requirements for the synthesis of different proteins, as well as the health and growth of tissues, particularly the small intestine and skeletal muscle. This knowledge is required to further develop more precise feeding programs for growing pigs.

\section{Impact of inflammation on amino acid intake, digestion, absorption and metabolism}

The meta-analysis by Pastorelli et al. (2012) quantified the impact of different experimental health challenges on growth and feed intake of swine. The authors showed that, compared to the growth performance of healthy pigs, all challenges negatively impacted growth rate and feed intake (figure 1). However, the range of the responses to the challenge was variable, indicating that the relative reduction in the average growth rate following a health challenge can be either totally or only partially associated with a reduction in feed intake. Actually, different challenges differentially affect feed intake, as well as the digestion, absorption and metabolism of nutrients, depending on which disturbance contributes to reducing growth rate and feed efficiency. As a result, animal nutritionists should adjust the composition of diets according to practical on-farm conditions and the challenging factors. By one side, a large quantity of several proteins related to inflammation may be synthesized in the body. Among them, the proteins secreted into the gut lumen are particularly relevant (see section 4 for more details), because some of them are neither digested nor recycled, and thus their AAs are definitively lost for the host and should be supplied adequately in the diet. This implies that adjustments to the dietary composition should be considered when nutritionists take into account how AAs support health maintenance and growth. On the other side, when growth restriction results mainly from reduced feed intake, energy supply may be more limiting for growth than a single nutrient. Thus, the adjustments of feed composition may not necessarily favor the restoration of animal health and growth. However, the provision of specific AAs involved in the control of feed intake may help to improve the health status of animals. This view is consistent with the report that dietary supplementation with $1 \mathrm{~g} \mathrm{L-Trp/kg}$ enhanced the feed intake of pigs challenged with the enterotoxigenic Escherichia coli K88 (ETEC), but had no effect on ETEC-resistant pigs (Trevisi et al., 2009). 
Intestinal inflammation can affect the absorption and transport of AAs by enterocytes into the blood.

In mice, a Trichinella spiralis infection reduced serum arginine (Arg) concentration and the intestinal expression of the SLC7A7 gene (Zhou et al., 2015) that encodes for the basolateral $\mathrm{y}^{+} L$ system transporter with an affinity for lysine (Lys), Arg, glutamine (Gln), histidine (His), methionine (Met) and leucine (Leu). This could be related to an increased use of Arg by the enterocytes. The perfusion of a solution containing ETEC into the jejunal loops from young pigs reduced the expression of genes encoding for apical (SLC7A9, SLC3A2,

SLC6A19) and basolateral (SLC7A7, SLC7A, SLC16A10) AA transporters, in association with the general upregulation of genes related to the induction of inflammation (Priori et al,. submitted). This finding could indicate that the acute inflammation induced by ETEC may reduce the intestinal absorption of some AAs as well as their concentrations in the blood.

Inflammation-induced changes in nitrogen metabolism have been extensively documented. In growing pigs, inflammation reduces $\mathrm{N}$ retention in the body and increases urinary $\mathrm{N}$ loss (van Heugten et al., 1994; Litvak et al., 2013; Campos et al., 2014; Rakhshandeh et al., 2014; Kampman-van de Hoek et al., 2015). These changes result from: (a) decreased feed intake, (b) impaired digestion and absorption of nutrients, (c) enhanced catabolism of body proteins, and (d) increased oxidation of AAs, and are orchestrated by inflammatory cytokines and hormones. The rate of protein synthesis decreases in the skeletal muscle, but increases in the liver and other tissues that are involved in the production of acute-phase (APP), defense and immune proteins (Obled et al., 2002). Thus, because of the different AA composition of synthesized proteins, inflammation modifies AA partitioning between the skeletal muscle and other organs or cell types, such as the liver, spleen, and digestive tract, and immune cells (Klasing and Johnstone, 1991; Obled et al., 2002; Le Floc'h et al., 2004). Losses of digestive enzymes and mucosal proteins and cell renewal increase during digestive disturbances, leading to increased losses of endogenous AAs that can be substantial for certain AAs, such as Arg, Leu, Thr, valine (Val), proline (Pro) (Adeola et al., 2016). In minipigs, acute inflammation of the intestine stimulates the uptake of luminal Thr and cysteine (Cys) by enterocytes (Rémond et al., 2009 and 2011) to support the synthesis of mucins (see section 3) and glutathione (GSH or L-Y-glutamyl-cysteinylglycine), a powerful antioxidant tripeptide (see section 4). During acute inflammation induced by intravenous endotoxin administration, the rate of muscle protein breakdown may exceed the rate of protein synthesis in 
the liver, resulting in greater AA catabolism and utilization for energy supply (Bruins et al., 2003). Increased expression of myostatin, a negative regulator of protein accretion, in skeletal muscle was reported in pigs infected with the porcine reproductive and respiratory syndrome (PPRS) virus, suggesting that muscle protein synthesis might be decreased by infection (Escobar et al., 2004). Accordingly, inflammation caused by turpentine injection decreased muscle protein synthesis, while hepatic fibrinogen synthesis increased by 140\% (Jahoor et al., 1999). The liver is involved in the synthesis of APPs, which serve important functions in restoring the cellular homeostasis of the immune system after infection or inflammation (Moshage, 1997). Therefore, the increase in APP synthesis may require muscle protein breakdown to supply AAs, and more specifically Trp and phenylalanine (Phe), because the profile of these AAs in APP differs from that of muscle protein (Reeds et al., 1994). Likewise, the synthesis of immunoglobulins (Ig) would require a great amount of Thr (Li et al., 1999) (see section 4).

Analysis of plasma AA responses to different challenges provides some indications on the changes in AA metabolism when health is compromised. Lower AA concentrations in plasma have been reported in pigs suffering from chronic lung inflammation, compared to healthy pair-fed pigs (Melchior et al., 2004), and also in pigs with infectious peritonitis (Yoo et al., 1997). Pigs co-infected with Mycoplasma hyopneumoniae and H1N1 virus exhibited alterations in the postprandial kinetics of glucose and AAs in plasma, indicating major changes in nutrient metabolism. More specifically, postprandial concentrations of Thr and Arg in plasma were much lower in co-infected pigs, compared to control healthy pigs (Le Floc'h et al., 2014). Tracer studies based on the infusion of labelled AAs revealed many metabolic changes that cannot be assessed by alterations in plasma AA concentrations. Indeed, plasma AA concentrations are greatly influenced by the nutritional status and dietary supply, and by the metabolic fluxes of AAs entering or leaving the plasma pool. Thus, modifications of the two opposite fluxes to the same extent would have no impact on plasma AA concentration. For instance, Val and tyrosine (Tyr) fluxes were decreased by experimentally induced lung inflammation without concomitant changes in their pool size in plasma (Kampman-van de Hoek et al., 2015).

\section{Amino acids and the physical gut mucosal barrier}


The intestine is a complex organ in which epithelial and secreting cells are closely associated to

134 immune cells. This complex cellular network, which includes secreted peptides and proteins and other host 135 defenses, contributes to the intestinal immune defense against invading pathogens, as well as to the 136 digestion and absorption of dietary nutrients. If the integrity of the digestive tract is compromised by inflammation (see section 2), digestive capacities and the mucosal barrier function will be impaired. The intestinal mucosal epithelium is a single layer of cells lining the gut that consists mainly of enterocytes and tight junctions (TJ) between enterocytes (Arrieta et al., 2006), which regulates traffic through this paracellular pathway and prevents the passage of pathogens. The TJ structure is formed by membrane proteins such as

occludin, members of the claudin family, and zonula occludens (ZO) proteins ZO-1, ZO-2 and ZO-3 (Arrieta et al., 2006). Dysregulation of the intestinal mucosal barrier due to stress (e.g., weaning), along with the invasion of pathogenic organisms and immunological challenges, has been reported to be associated with multiple diseases (Groschwitz and Hogan, 2009; Camilleri et al., 2012; Bergmann et al., 2013). Consequently, earlyweaned pigs commonly experience diarrhea caused by impaired mucosal barrier function, as indicated by reductions in jejunal transepithelial electrical resistance and elevations in paracellular permeability up to $40 \%$ (Campbell et al., 2013; Wang et al., 2015). An increase in intestinal permeability is associated with villus atrophy and significant reductions in the jejunal expression of occludin, claudin-1, ZO-2, and ZO-3 (Wang et al., 2015).

Half of all proteinogenic AAs have been shown to exert positive effects on gut villus morphology when supplied slightly above the estimated requirements. Attenuation of villus atrophy has been described for aspartate (Asp) (Pi et al., 2014; Wang et al., 2016), Arg (Zhu et al., 2013), Gln (Wu et al., 1996b; Yi et al., 2005; Noth et al., 2013), glutamate (Glu) (Rezaei et al., 2013), Pro (Wu et al., 2011), glycine (Gly) (Wang et al., 2014b), Lys (Wang et al., 2009; He et al., 2013), Met (Chen et al., 2014), Thr (Ren et al., 2014) and Trp (Koopmans et al., 2006) (Figure 2). Threonine is the major substrate for synthesis of mucosal glycoproteins (mucins) and, therefore, for maintenance of gut barrier integrity (Bertolo et al 1998; Hamard et al 2007). In addition, a number of AAs, such as Asp (Wang et al., 2016), Gln (Noth et al., 2013), Glu (Jiao et al., 2015), Gly (Li et al., 2016), and Met (Chen et al., 2014), play critical roles in supporting gut integrity and function due to their ability to increase the expression of TJ proteins. Therefore, the intestinal mucosal barrier function could 
be improved during inflammatory processes, including the post-weaning stress syndrome (Jiao et al., 2015)

by supplementing the piglet diet with the aforementioned AAs. Dietary AAs stimulate intestinal cell proliferation via several mechanisms. Under challenging conditions, oral Arg supplementation was shown to activate the mTOR signaling pathway in the intestinal tissue (Corl et al., 2008). Of particular interest, Gln stimulates protein synthesis and inhibits proteolysis in enterocytes by activating the mTOR pathway (Xi et al., 2012), up-regulating ornithine decarboxylase expression to increase the production of polyamines, which are required for DNA and protein synthesis (Wu et al., 2013a). Furthermore, Gln is a precursor for the synthesis of purine and pyrimidine nucleotides, which are essential for DNA synthesis and the proliferation of cells (Wu, 1998). Glutamine enhances the expression of genes for mitogen-activated protein kinases, resulting in the activation of gene transcription, thereby contributing to cell proliferation in the intestinal epithelium (Rhoads et al., 1997). Glutamine metabolism also provides ATP to support intestinal ion transport, cell growth and migration, thereby maintaining intestinal integrity (Curi et al., 2005; Wu et al. 2011).

The major products of sulfur AA metabolism are GSH, homocysteine and taurine (Tau). Glutathione, which is synthesized from cysteine (Cys), Gly and Glu, contributes to higher rates of cell proliferation, whereas Tau plays an important role in membrane stabilization (see section 5) and anti-oxidative reactions (Wang et al., 2009, Wu et al., 2013b). Apart from improving the intestinal morphology and cell proliferation, dietary AAs have beneficial effects on the physical gut barrier. For instance, Arg is an essential precursor for the synthesis of important compounds, including nitric oxide (NO), polyamines, and creatine (Wu and Morris, 1998). Therefore, this AA mediates vasodilation, intestinal fluid secretion, and whole-body energy metabolism. In addition, Arg is of critical importance for the maintenance of intestinal mucosal barrier function. The roles of Arg are separately described in Chapter 6 . Asparagine may also improve the intestinal energy status, as indicated by: (a) increases in the concentrations of ATP, ADP and total adenine nucleotides and in adenylate energy charge; (b) a decrease in the AMP/ATP ratio; and (c) increases in the activities of tricarboxylic acid cycle enzymes (Pi et al., 2014) or ileal diamine oxidases (Wang et al., 2016). Supplementation of GIn promoted cell survival by stimulating the expression of heat shock proteins (Rhoads and $\mathrm{Wu}, 2009$ ) and anti-oxidative genes (Wang et al. 2008). Furthermore, supplementation of Gln recycled cellular proteins and organelles by promoting autophagy in epithelial cells (Sakiyama et al., 2009), and 
187 inhibited the intestinal expression and activation of nuclear factor-kB (Haynes et al., 2009; Mondello et al., 2010).

Based on current knowledge, Arg, Gln, Glu, Gly, sulfur AA, and Thr are promising for the nutritional

management of a wide array of inflammatory processes that affect the physical gut barrier and the resultant gut-related disorders in pigs. However, there is a lack of studies about the involvement of AAs, other than the Arg family of AAs, in the regulation of intestinal health. Such research is warranted to identify dietary supplementation with appropriate AAs as an alternative approach to reduce the preventive use of feed antibiotics in animal production in the future.

\section{Amino acids as primary constituents of defense proteins}

Data showing the specific needs of AAs as primary constituents of proteins involved in defense and protection functions at the gut level (antibacterial proteins, IgA and IgM, mucins) are scarce. Nevertheless, ensuring that dietary AAs do not limit the synthesis of specific protective proteins is relevant for gut health. Several of these proteins are structural complexes, and undergo post-transcriptional modifications to fulfill their biological functions, for example conferring the proteins an ability to conjugate pathogens or reducing the intracellular degradation of the proteins. The presence of asparagine (Asn), serine (Ser), and Thr sequences is important for $\mathrm{N}$-glycosylation in the endoplasmic reticulum and $\mathrm{O}$-glycosylation in the Golgi apparatus (Blom et al., 2004). Thus, certain AAs confer specific properties to these functional proteins. The fact that such specific AAs are more abundant in those proteins than in the average body protein is highly relevant for developing dietary interventions to stimulate the synthesis of the aforementioned proteins.

The most abundant AAs in some mucins, immunoglobulins, and other intestinal defense proteins are summarized in Table 1. These values were calculated from their AA composition obtained from the gene sequence reported in the Ensemble database for pigs (or for human when the sequence was not available). In general, the amount of Thr in endogenous protein losses, particularly in young pigs (Adeola et al., 2016), agrees with the abundance of this AA, representing $16 \%$ of total AAs in mucins (Lien et al., 1997). Data in Table 1 also help to understand some conflicting results about the requirement for Thr during digestive disorders in pigs. In neonate pigs, adequate Thr is critical to maintain the necessary mucin production (Law 
et al., 2007). Experimentally induced ileitis increased the utilization of arterial-blood Thr by the portal-drained viscera, and ileal mucin synthesis in mini pigs (Rémond et al., 2009). However, when the dietary ratio of Thr:Lys was increased from $65 \%$ to $70 \%$, ETEC-susceptible weaned pigs orally challenged with ETEC did not exhibit a change in the total mucin content in jejunal mucosal scrapings (Trevisi et al., 2015a). The lack of an effect of supplementary Thr can be explained, in part, by the fact that mucin-13, which is mainly expressed in the jejunum of pigs, is not rich in Thr, in contrast to other mucins that are dominant in other segments of the gastrointestinal tract.

The most abundant $\mathrm{AA}$ in the $\operatorname{Ig} \mathrm{A}$ and $\operatorname{IgM}$ proteins and in the protein joining multimeric $\lg A$ and $\operatorname{IgM}$ is Thr (Tenenhouse and Deutsch, 1966). In healthy pigs injected with bovine serum albumin or swine feverattenuated vaccine (Li et al., 1999) or ovalbumin (Wang et al., 2006), serum IgG concentrations increased with dietary Thr intake, as observed for serum IgG and IgM in healthy weaned pigs, but not for piglets challenged with the porcine pseudorabies live vaccine (Mao et al., 2014a). Supplementation of Thr increased IgG and interleukin-1 $\beta$ jejunal concentrations in serum after an ETEC challenge (Ren et al., 2014). Increasing dietary Thr content from $8.5 \mathrm{~g} / \mathrm{kg}$ to $9.0 \mathrm{~g} / \mathrm{kg}$ (beyond the current requirement) with addition of L-Thr resulted in a higher secretion of IgM in ETEC-challenged pigs susceptible to ETEC, while this was not seen in infected non-susceptible pigs (Trevisi et al., 2015a). In the latter, IgM and IgA concentrations in blood did not rise after the challenge. This result indicates that the effect of dietary provision of Thr on the humoral immune response depends on the health status and genetic background of pigs.

The first limiting AA affecting the synthesis of several porcine defense and antibacterial proteins or polypeptides can be predicted from their AA composition. It has been reported that Ser is a major AA for the synthesis of regenerating islet-derived protein 3 gamma (REG3G), a C-type lectin that targets Gram-positive bacteria and is abundantly produced in the porcine small intestine during certain intestinal infections (Soler et al., 2015). Serine is classified as a nutritionally nonessential AA; however, it is the major metabolic source of the one-carbon pool (Kalhan and Hanson, 2012) and the pathway for its synthesis from glucose uses Glu, whose metabolism is in turn affected by Ser requirement. Inadequate provision of Ser can result in impaired synthesis of Gly (Wu, 2013), with consequent nutritional imbalance of other AAs (Wang et al., 2013). Another important antibacterial protein that has not received much consideration for nutritional requirements is 
241 lysozyme, which contains a high proportion of Leu. To date, there is no information on the impact of dietary

242 leucine intake on lysozyme production in literature. On the whole, paying attention to AA composition and 243 to the AAs that potentially limit the production of defense proteins would advance studies aimed at meeting 244 AA requirements to sustain animal growth under sub-optimal rearing conditions. Furthermore, these proteins could be considered as potential biomarkers in blood, saliva, feces or other tissue samples to assess intestinal health and function in pigs subjected to different feeding strategies.

\section{Amino acid involved in the antioxidant defense}

Oxidative stress results from an imbalance between the endogenous production of reactive oxygen species (ROS) and antioxidant defenses (Wu et al., 2004a). Endogenous ROS are produced within mitochondria during cell respiration and thus are normal products of cellular oxygen metabolism. Besides, the production of ROS is a mechanism used by some immune cells (e.g., macrophages) to exert their cytotoxic function. Thus, ROS production during inflammation and the activation of innate immune response are defense mechanisms that can generate oxidative stress when antioxidant defenses are overwhelmed (Li et al., 2007). Finally, ROS can be produced after animals are exposed to pollutants and xenobiotics but their impact on farm animals is not fully understood. As previously mentioned in section 2 , one of the most powerful endogenous antioxidant components is GSH (Malmezat et al., 1998). In postnatal pigs, the liver and gut seem to be the two major sites for GSH synthesis (Wu et al., 2004a; Bauchart-Thevret et al., 2011; Rémond et al., 2011). In the liver of rats, the synthesis of Cys from methionine during inflammation increases to support the greater demand for GSH (Malmezat et al., 2000), but Met provision does not appear to be sufficient for GSH production. In growing pigs, repeated injections of endotoxin increased the conversion of Cys into GSH and taurine, while decreasing the catabolism of Cys into sulfate (Rakhshandeh and de Lange, 2010; Rakhshandeh et al., 2010). In mini-pigs, experimental ileitis increased liver and ileal GSH synthesis during the acute phase of inflammation, and increased the whole-body flux of Cys (Rémond et al., 2011). Cysteine supplementation through organ infusion positively influenced the pool of GSH in the liver (Budzinski et al., 2011). Under practical conditions, feeding strategies based on the addition of stable precursors of Cys (e.g., $\mathrm{N}$-acetyl-cysteine) in feed may be relevant. Likewise, the addition of Met, its hydroxyanalogue HMTBA 
(2-hydroxy-4-(methylthio)butanoate), total sulfur AAs (Met + Cys), or N-acetyl-cysteine to diets also help maintain the intracellular GSH pool, as well as intestinal redox status and integrity in weaned pigs (BauchartThevret et al., 2009; Chen et al., 2014; Li et al., 2014; Xu et al., 2014; Hou et al., 2015a).

Other AAs have been reported to reduce the consequences of oxidative stress in cells, particularly in 272 enterocytes. For instance, supplementation with Glu (Rezaei et al., 2013; Jiao et al., 2015) and Gly (Wang et al., 2014a; Jiao et al., 2015), the two other AAs that constitute GSH, as well as Arg (Zheng et al., 2013) and Asp (Yin et al., 2015; Duan et al., 2016), alleviated the consequences of oxidant-induced oxidative stress on intestinal function, AA transporters, redox status, and growth. In the whole animal, a reduction of oxidative stress may result also from the contribution of these AAs because of their pivotal metabolic roles in immune and intestinal cells besides their direct antioxidant effect (Li et al., 2007; Wu, 2013). Likewise, Trp (see section 7) may exert a direct antioxidant effect, and several Trp metabolites, produced through the kynurenine and melatonin biosynthesis pathways, act as free radical scavengers and have antioxidant properties (Christen et al., 1990; Goda et al., 1999). In this way, Mao et al., (2014b) showed that Trp supplied above the recommendation $(3.0 \mathrm{~g} / \mathrm{kg}$ vs $1.8 \mathrm{~g} / \mathrm{kg}$ ) alleviated oxidative stress induced by intraperitoneal administration of diquat (an herbicide) in piglets.

\section{Amino acids related to the arginine - nitric oxide (NO) pathway}

Sow's milk is rich in Gln, Glu and Pro (Wu and Knabe, 1994). Specifically, concentrations of free Gln in the milk increase progressively with advancing lactation, and free- and peptide-bound GIn plus Glu account for $20 \%$ of total amino acids. In contrast, the concentrations of Arg in sow's milk (free plus peptide-bound) are much lower than those of GIn plus Glu and Pro on all days of lactation. Thus, sow's milk provides at most only $40 \%$ of the Arg needed for metabolic utilization by young pigs (Wu et al., 2004b). In vivo studies involving the cannulation of the jejunal artery and jejunal vein of 14- to 58-day-old pigs have shown that the small intestine actively utilizes dietary and arterial-blood Gln, and releases citrulline and, to a lesser extent, $\operatorname{Arg}$ (Wu et al., 1994a) (Figure 3). The only AA in arterial blood that is taken up by the small intestine of pigs in the postabsorptive state is $\mathrm{Gln}$ (Wu et al., 1994a). Enterocytes synthesize citrulline and Arg from 0.5 - $5 \mathrm{mM}$ Gln via pyrroline-5-carboxylate synthase (Wu et al., 1994b) and from 0.5 -2 mM Pro via proline oxidase (Wu, 1997) 
in a dose-dependent manner. The de novo synthesis of $\operatorname{Arg}$ is consistent with the conversion of $\left[\mathrm{U}-{ }^{14} \mathrm{C}\right] \mathrm{Gln}$ 296 into $\left[{ }^{14} \mathrm{C}\right] \mathrm{Arg}$ in the enterocytes of 0- to 7-day-old pigs (Blachier et al., 1993). All substrates required for these 297 synthetic pathways, including ammonia, $\mathrm{HCO}_{3}^{-}, \mathrm{Glu}, \mathrm{Asp}$, and ATP, are produced from Gln catabolism (Wu 298 and Morris, 1998). Because there is no uptake of arterial- blood Pro by the pig small intestine (Wu et al., 299 1994a), enteral provision of large amounts of Pro from sow's milk and the postweaning diet is crucial for the 300 compensation of Arg deficiency in the diets (Brunton et al., 1999; Bertolo et al., 2003). In young and adult expression of $\mathrm{N}$-acetylglutamate synthase in enterocytes (Wu et al., 2004b; Zhang et al., 2014). This enzyme catalyzes the production of $\mathrm{N}$-acetylglutamate (from Glu and acetyl-CoA) that is an allosteric activator of carbamoylphosphate synthase-I for the formation of citrulline and arginine (Wu and Morris 1998).

The discovery of the synthesis of NO (a major vasodilator, a signaling molecule, and a mediator of immune response) from Arg has renewed interest in Arg nutrition research over the past 25 years (Hou et al., 2015b, 2016a; Wu et al., 1996a). Based on the results of recent studies which indicate that supplementation with Arg to conventional diets can improve the growth or production performance of modern breeds of pigs during gestation, lactation, nursery, weaning, and growing-finishing periods (Wu et al., 2007; Wu, 2014), the NRC now recognizes that Arg is a conditionally essential AA for pigs in all phases of their production. Thus, NRC (2012) has recommended the requirements of Arg in diets for pigs in all the phases of production, which ranged from $0.17 \mathrm{~g} / \mathrm{kg}$ for early-gestating sows to $0.68 \mathrm{~g} / \mathrm{kg}$ for nursing pigs, on the standardized ileal digestible basis. Higher values of dietary Arg requirements than NRC (2012) were suggested by Wu (2014) to maximize the growth performance, milk production, and embryonic/fetal survival of pigs.

As noted previously in sections 3 and 5 , Arg has many roles: protecting against oxidative stress and inflammation, activating mTOR in intestinal tissue, modulating the intestinal inflammatory response, and attenuating villus atrophy. As a functional AA, Arg has a wide range of applications in swine production (Hou et al., 2016b). For example, in neonatal pigs, dietary supplementation with $0.2 \%$ and $0.4 \%$ Arg to 7 - to 21 -dold milk-fed pigs, artificially reared on a liquid-milk feeding system, dose-dependently enhanced plasma Arg concentrations (30\% and $61 \%)$, reduced plasma ammonia levels ( $20 \%$ and $35 \%$ ), and promoted weight gain 
$0.8 \%$ Arg to a milk replacer diet enhanced the weight gain of 4 - to 24 -day-old piglets by $19 \%$ and $22 \%$, respectively, without affecting feed intake. Of interest, supplementation of the preweaning diet with Arg improved intestinal growth and development after termination of the period of supplementation, in 25- to 45-day-old pigs (Yang et al., 2016). In weanling pigs, supplementing 0.6\% Arg to a corn- and soybean mealbased diet increased small-intestinal mass by $89 \mathrm{~g}$ and daily weight gain by $42 \mathrm{~g} / \mathrm{d}$, in 21- to 28-day-old weanling piglets (Wu et al., 2010). Dietary Arg supplementation also increased the splenic expression of IL-8 and tumor necrosis factor- $\alpha$, indicators of the activation of innate immunity, as well as the serum concentrations of IgG and IgM, to prevent infections in weanling pigs (Li et al., 2007; Tan et al., 2009a). Likewise, Arg supplementation prevented the death of porcine enterocytes induced by $E$. coli endotoxin through mechanisms involving the activation of mTOR and the suppression of toll-like receptor-4 signaling 333 (Tan et al., 2010). supplementation enhances feed efficiency, fertility and lactation in swine. For example, supplementing $1 \%$ Arg to a corn- and soybean meal-based diet for 60 days reduced whole-body white fat content by $11 \%$ in growing-finishing pigs, while increasing the skeletal-muscle content in their whole body by $5.5 \%$, without

Owing, in part, to improvements in anti-oxidative response and whole-body health, Arg affecting daily weight gain (Tan et al., 2009b). Furthermore, supplementing $0.5 \%$ and $1 \%$ Arg to a corn- and soybean meal-based diet containing $0.95 \% \mathrm{Arg}$, for growing-finishing pigs dose-dependently reduced lipid peroxidation in skeletal muscle and improves meat quality at $48 \mathrm{~h}$ postmortem (Ma et al., 2010). In gestating pigs, dietary supplementation with $1.0 \% \mathrm{Arg}-\mathrm{HCl}$ between days 30 and 114 of gestation increased concentrations of Arg, ornithine, and Pro in plasma by $77 \%, 53 \%$, and $30 \%$, respectively, as well as the number of live-born piglets by two and litter birth-weight by $24 \%$ (Mateo et al., 2007). This effect of Arg is associated with (a) the improved health of the conceptus (embryo/fetus and associated membranes) due to the amelioration of oxidative stress, and (b) enhanced placental angiogenesis and vasculature, which is stimulated by physiological levels of NO (50-500 nM; Wu and Meininger 2009; Wu et al., 2013b), to remove oxidants from the fetus. Similarly, dietary supplementation with $1 \%$ Arg between days 14 and 28 of gestation enhanced the number of fetuses per litter by 3.7 on day 70 of gestation in superovulated gilts, as well as fetal 
muscle development (Bérard and Bee, 2010). Of note, Arg supplementation to gestating sows enhanced the

production of NO and B lymphocyte-derived antibodies, thereby preventing morbidity and mortality in

response to the intestinal infection caused by Brachyspira hyodysenteria, the swine dysentery pathogen (Li

352 et al., 2007). In lactating primiparous sows, supplementing $0.83 \%$ Arg to the diets augmented average pig weight gain by $0.26 \mathrm{~kg}$ in the first week of lactation and by $0.42 \mathrm{~kg}$ during a 21 -day suckling period (Mateo et al., 2008). This effect of Arg may be mediated, in part, by NO-induced increase in blood flow into the mammary gland (Kim and Wu, 2009). Furthermore, dietary Arg supplementation to sows promoted milk lipid production (Kirchgessner et al., 1991), and improved the sow feed efficiency, particularly under hot environmental temperatures (Laspiur and Trottier, 2001). Taken together, these findings underscore the need to carefully consider dietary Arg intake to improve the health, growth, survival, lactation and fertility in swine. This is particularly noteworthy, because low-protein diets, which are currently used to reduce the production of nitrogenous wastes by swine farms, do not sufficiently supply Arg or its AA precursors (Wu et al., 2014a).

\section{Tryptophan and the kynurenine pathway}

Tryptophan is the precursor of kynurenine, the first metabolite of a complex metabolic pathway ending in the formation of quinolinic acid, niacin and nicotinamide, kynurenic and xanthurenic acids (Le Floc'h et al., 2011). Two enzymes are needed to convert Trp into kynurenine. The first enzyme is Trp 2,3-dioxygenase (TDO) located in the liver and responsible for the degradation of Trp in excess. The second enzyme is indoleamine 2,3-dioxygenase (IDO) found in numerous immune cells like macrophages and dendritic cells. Interferon $\gamma$, an inflammatory cytokine, stimulates IDO expression and activity (Popov and Schultze, 2008).

Activation of IDO and increased Trp catabolism are known as a mechanism for regulating the immune system during pregnancy and diseases (Munn and Mellor, 2013; Badawy et al., 2016) and for immune tolerance. This notion originates from the discovery of the protective role of IDO during human gestation through the prevention of the fetal rejection by maternal T-lymphocytes (Munn et al., 1998). The activation of IDO and the subsequent production of Trp metabolites with cytotoxic activity would contribute to reducing T-cell proliferation. Moreover, IDO expression by dendritic cells is associated with the acquisition of a 
regulatory phenotype, leading to immune tolerance (Sharma et al., 2007). The activation of IDO is also

thought to be involved in long-lasting immune activation that occurs with some inflammatory diseases (Popov and Schultze, 2008). In pigs, experimental data have confirmed that inflammation increases IDO activity and this induction is concomitant with lower plasma Trp concentrations (Melchior et al., 2004; Melchior et al., 2005; Wirthgen et al., 2014). The impact of inflammation on plasma Trp concentration and tissue IDO activity is greater when Trp is supplied below the nutritional recommendations (Le Floc'h et al., 2008). Additionally, oxidative stress, a mechanism associated with the inflammatory response, also depressed plasma Trp and increased plasma kynurenine in weaned pigs (Lv et al., 2012). Such modifications in Trp metabolism are expected to affect Trp availability for growth. Indeed, repeated LPS injections reduced the availability of Trp for body protein deposition and growth (de Ridder et al., 2012). Accordingly, if additional crystalline Trp did not completely prevent growth restriction caused by poor health status, the improvement of growth through supplementing Trp to a low-Trp diet was greater for pigs with compromised health than for pigs with good health (Le Floc'h et al., 2010). The response to dietary Trp supplementation can be affected by the presence of individual genetic predisposition to $E$. coli infections in pigs. Indeed, the susceptibility to ETEC adhesion to jejunal villi is required for the development of the pathology and it is genetically transmitted. In the first 4 days after experimental infection, dietary supplementation with $1 \mathrm{~g}$ Trp/kg beyond the minimal nutrient requirement improved growth response in weaned pigs genetically predisposed to ETEC K88, but not in non-susceptible pigs (Trevisi et al., 2009).

The dramatic changes in Trp metabolism induced by inflammation are clearly associated with the functional role of this AA during inflammatory states. Pigs suffering from experimentally induced lung inflammation had lower APP concentrations and had less severe lung lesions when they were fed a diet with a small excess of Trp compared to pigs fed a diet moderately deficient in Trp (Le Floc'h et al., 2008). At the same time, IDO activity was also lower in pigs fed the higher Trp diet, indicating that inflammation was alleviated by dietary Trp supplementation. In a porcine model of induced colitis, Trp supplementation downregulated inflammation, restored the local immune response and reduced colitis symptoms (Kim et al., 2010). At present, the positive effect of dietary Trp on the inflammatory response remains unexplained. However, it could be speculated that dietary Trp may help to control the inflammatory response. As previously 
mentioned (see section 5), Trp and some of its metabolites produced along the kynurenine pathway, 3-

404 hydroxy-anthralinic acid and 3-hydroxy-kynurenine, may have antioxidant properties (Christen et al., 1990).

405 This hypothesis is supported by the recent finding that liver TDO activity was increased by oxidative stress 406 (Lv et al., 2012; Mao et al., 2014b). Recently, in Large White pigs, polymorphism was identified in the KMO 407 gene coding for kynurenine 3-monooxygenase that hydroxylates kynurenine to 3-hydroxy-kynurenine; the 408 polymorphism for the genotype for $K M O$ affected the extent to which the plasma levels of kynurenine and kynurenic acid were elevated in response to Trp supplementation (Trevisi et al., 2015b). Furthermore, the 3hydroxykynurenine/kynurenic acid ratio in plasma, representing the different actions of KMO and kynurenic acid transaminase enzymes, differed among the different genetic variants for $K M O$. This implied that the response of pigs to dietary Trp levels could be influenced by the genetic background as recently suggested

(Le Floc'h et al. 2017) and by their ability to produce different kynurenine metabolites during inflammatory states.

\section{Functional amino acids and feeding strategies}

Environmental, social and economic reasons justify the demand for higher feed efficiency and more specifically nitrogen-utilization efficiency in animal production (Wu et al., 2014c). A strategy to improve protein utilization in pigs and to prevent gut disorders is the reduction of dietary crude protein (CP) concomitant with adequate supplementation of free AAs. Gloaguen et al. (2014) confirmed the efficacy of this strategy and the possibility to formulate very low-CP (13.5\%) diets that maintain the growth of 10 to 20 kg pigs through the inclusion of free AAs. Furthermore, moderate dietary protein restriction (CP 13-15.3\%) was demonstrated to be beneficial for a healthy balance in the gut microbiota and metabolic activity in the large intestine of pigs, and improved ileal mucosal barrier function (Fan et al., 2017; Peng et al., 2017). The reduction in dietary $\mathrm{CP}$ content allows for reduction in nitrogen intake and may avoid AA excesses, thereby preventing excessive metabolic loads. Besides reductions in the use of feed antibiotics, low CP diets may provide an opportunity to supply specific functional AAs that would also contribute to limiting metabolic disturbances associated with inflammatory states. Functional AAs are defined as those AAs that regulate key metabolic pathways to improve health, survival, growth, development, lactation, and reproduction of 
organisms (Wu, 2010) or which form biologically active peptides or proteins. These AAs include those that can be synthesized and those that cannot be synthesized de novo in animal cells.

Dietary free AAs appear in the peripheral plasma more quickly than AAs arising from intact proteins (Yen et al., 2004). Yen et al. (2004) reported maximal portal and arterial plasma Lys and Thr concentrations in pigs $1 \mathrm{~h}$ postprandial with the provision of free AAs, while the peak level for protein-bound AAs occurred at $2.5 \mathrm{~h}$ postprandial. The difference in the time of appearance of AAs in the peripheral blood, which results from their provision in different forms, may be a physiological basis for preventive or therapeutic nutritional intervention via addition of single AAs or AA blends to drinking water or the feeding system. Besides, supplemental AAs, such as free Arg, Gln, Glu, Gly, and Trp, enter the lumen of the small intestine and are taken up rapidly by the gut, where they regulate gene expression, cell signaling, antioxidative responses, and immunity (Wu, 2009). Temporary, targeted provision with functional AAs as powder on top of the commercial diet might be beneficial to overcome intestinal dysfunction during critical periods of production, such as weaning stress or pathogen exposure. For example, Le Floc'h et al. (2008) reported that inflammation increased Trp catabolism and thus decreased Trp availability for growth (see section 7). Consequently, it may be assumed that the targeted provision of free Trp beyond the requirements for growth may contribute to a steady level of plasma Trp and therefore an increased availability for immune response and muscle growth.

Much attention has recently been directed to studying Leu signaling in animal nutrition. For example, pulsatile delivery of Leu to neonatal pigs fed a milk replacer orogastrically increases lean growth by $25 \%$ (Boutry et al., 2016), likely due to insulin-stimulated translation initiation (Davis et al., 2015). Wilson et al. (2009) demonstrated that ingestion of a meal providing one-sixth of the daily dietary Leu requirements provoked the most rapid stimulation of muscle protein synthesis with highly efficient peak activation within 30 min. Consequently, with pulsatile supplementation with a functional AA, frequent or ad libitum feeding to the healthy pig should be the preferred feeding strategy in order to guarantee a balanced supply of AAs, leading to similar rates of oxidation of excess essential AAs from diets containing either free or protein-bound AAs.

As described previously for Trp, the response of animals to dietary Leu and GIn in terms of whole body growth depends on the health status and production level of the pig. Frost and Lang (2011) estimated 
457 a threshold for dietary Leu that was higher during inflammation than under healthy conditions. Inflammation

458 has been reported to reduce the sensitivity of skeletal muscle to Leu (Lang and Frost, 2005), thereby impairing 459 muscle protein synthesis via the mTOR signaling pathway. Furthermore, Leu could act as an N donor for synthesis of Gln, which is considered to be a conditionally essential AA during weaning (Wu et al., 1996b) or disease (Karinch et al., 2001) but promotes Leu uptake by the muscle as well. Therefore, targeted additional administration of Leu and Gln might alleviate weight loss during disease by maintaining muscle protein synthesis. However, whether these findings could have practical applications for swine production remains to be determined. Based on the current literature, the provision of particular AAs may be useful to target specific AA functions with a flexibility to adjust age- or health status-specific requirements of the animals.

\section{Future perspectives}

Besides being the building blocks of proteins, AAs are also precursors for the synthesis of bioactive peptides and low-molecular-weight metabolites with major physiological and regulatory functions in animals. Because the small intestine is the terminal site for nutrient digestion and absorption and yet is highly susceptible to infection, inflammation, and injury, there has been growing interest in the use of specific AAs to improve intestinal health, integrity, and function in swine at the various stages of physiological development and during various phases of pork production $(\mathrm{Wu}, 2018)$. While it is well established that swine diets must contain essential AAs, adequate provision of traditionally classified non-essential AAs (e.g., $\operatorname{Arg}, \mathrm{Glu}, \mathrm{Gln}$, and Gly) is also critical to ensure optimum intestinal and whole-body health, growth rate and feed efficiency in pigs. The term "nutritionally non-essential AA" has now been recognized as a misnomer in nutritional sciences, and animals (including growing, gestating and lactating pigs, as well as gilts and boars) have dietary requirements for those AAs (Hou and $\mathrm{Wu}, 2017$ ). The availability of feed-grade crystalline AAs, particularly functional AAs, for supplementation to low-protein diets is expected to play an important role in the sustainability of pig production worldwide to limit the negative impact of pig production on the environment (Garcia-Launay et al., 2014), while meeting the increasing demand for human consumption of high-quality animal protein (Wu et al., 2014b and 2014c). 
The recent progress on the "omic" sciences has provided insights into AA metabolism in animals, 484 including swine. These high-throughput studies, including targeted gene association studies and 485 metabolomic approaches, have resulted in a better understanding of the gut microbiota and in the 486 identification of gene markers for important transmissible diseases. The advanced methodologies will further 487 stimulate research to better define dietary AA requirements for pigs with different phenotypes and 488 genotypes.

\section{Acknowledgments}

This work was promoted inside the COST Action FA1401 "PIGUTNET". Research in G. Wu's laboratory was supported by Agriculture and Food Research Initiative Competitive Grants (2014-67015-21770 and 201567015-23276) from the USDA National Institute of Food and Agriculture, and by Texas A\&M AgriLife Research (H-8200).

\section{References}

Adeola, O., Xue, P. C., Cowieson, A. J., Ajuwon, K. M., 2016. Basal endogenous losses of amino acids in protein nutrition research for swine and poultry. Animal Feed Sci. Technol. 221, 274-283. DOI: 10.1016/j.anifeedsci.2016.06.004.

Arrieta, M., Bistritz, L., Meddings, J., 2006. Alterations in intestinal permeability. Gut 55, 1512-1520. DOI: 10.1136/gut.2005.085373.

Badawy, A. A., Namboodiri, A. M., Moffett, J. R., 2016. The end of the road for the tryptophan depletion concept in pregnancy and infection. Clin. Sci. 130, 1327-1333. DOI: 10.1042/CS20160153.

Bauchart-Thevret, C., Stoll, B., Chacko, S., Burrin, D.G., 2009. Sulfur amino acid deficiency upregulates intestinal methionine cycle activity and suppresses epithelial growth in neonatal pigs. Am. J. Physiol. Endocrinol. Metab. 296, E1239-E1250. DOI: 10.1152/ajpendo.91021.2008. 
Bérard, J., Bee, G., 2010. Effects of dietary L-arginine supplementation to gilts during early gestation on foetal survival, growth and myofiber formation. Animal 4, 1680-1687. DOI: 10.1017/S1751731110000881

Bergmann, K., Liu, S., Tian, R., Kushnir, A., Turner, J., Li, H-L., Chou, P.M., Weber, C.R., De Plaen, I.G., 2013. Bifidobacteria stabilize claudins at tight junctions and prevent intestinal barrier dysfunction in mouse necrotizing enterocolitis. Am. J. Pathol. 182, 1595-1606. DOI: 10.1016/j.ajpath.2013.01.013.

Bertolo, R., Chen, C., Law, G., Pencharz, P., Ball, R., 1998. Threonine requirement of neonatal piglets receiving total parenteral nutrition is considerably lower than that of piglets receiving an identical diet intragastrically. J. Nutr. 128, 1752-1759.

Bertolo, R.F.P., Brunton, J.A., Pencharz, P.B., Ball, R.O., 2003. Arginine, ornithine, and proline interconversion is dependent on small intestinal metabolism in neonatal pigs. Am. J. Physiol. 284: E915-E922. DOI: 10.1152/ajpendo.00269.2002.

Blachier, E., M'Rabet-Touil, H., Posho, L., Darcy-Vrillon, B., Duee, P.H., 1993. Intestinal arginine metabolism during development. Evidence for de novo synthesis of L-arginine in newborn pig enterocytes. Eur. J. Biochem. 216, 109-117.

Blom, N., Sicheritz-Pontén, T., Gupta, R., Gammeltoft, S., Brunak, S., 2004. Prediction of post-translational glycosylation and phosphorylation of proteins from the amino acid sequence. Proteomics 4, 1633-1649. DOI: $10.1002 /$ pmic.200300771.

Boutry, C., El-Kadi, S.W., Suryawan, A., Steinhoff-Wagner, J., Stoll, B., Orellana, R.A., Nguyen, H.V., Kimball, S.R., Fiorotto, M.L., Davis, T.A., 2016. Pulsatile delivery of a leucine supplement during long-term continuous enteral feeding enhances lean growth in term neonatal pigs. Am. J. Physiol. Endocrinol. Metab. 310, E699-E713. DOI: 10.1152/ajpendo.00479.2015.

Bruins, M. J., Deutz, N.E., Soeters, P.B., 2003. Aspects of organ protein, amino acid and glucose metabolism in a porcine model of hypermetabolic sepsis. Clin. Sci. 104, 127-141. DOI: 10.1042/CS20020275.

Brunton, J.A., Bertolo, R.F.P., Pencharz, P.B., Ball, R.O., 1999. Proline ameliorates arginine deficiency during enteral but not parenteral feeding in neonatal pigs. Am. J. Physiol. Endocrinol. Metab. 277, E223-E231. 
Budzinski, G. Suszka-Świtek, A., Caban, A., Oczkowicz, G., Heitzman, M., Wystrychowski, W., Dolińskac, B., Ryszkad, F., Cierpka, L., 2011. Evaluation of cysteine effect on redox potential of porcine liver preserved by simple hypothermia. Transplant. Proc. 43, 2897-2899. DOI: 10.1016/j.transproceed.2011.08.065.

Camilleri, M., Madsen, K., Spiller, R., Greenwood-Van Meerveld, B., Verne, G., 2012. Intestinal barrier function in health and gastrointestinal disease. Neurogastroenterol. Motil. 24, 503-512. DOI: 10.1111/j.1365-2982.2012.01921.x.

Campbell, J., Crenshaw, J., Polo, J., 2013. The biological stress of early weaned piglets. J. Anim. Sci. Biotechnol. 4, 19. DOI: 10.1186/2049-1891-4-19.

Campos, P. H., Labussière, E., Hernández-García, J., Dubois, S., Renaudeau, D., Noblet, J., 2014. Effects of ambient temperature on energy and nitrogen utilization in lipopolysaccharide-challenged growing pigs. J. Anim. Sci. 92, 4909-4920. DOI: 10.2527/jas.2014-8108.

Capozzalo, M. M., Resink, J. W., Htoo, J. K., Kim, J. C., de Lange, F. M., Mullan, B. P., Hansen, C. F., Pluske, J. R. 2017. Determination of the optimum standardised ileal digestible sulphur amino acids to lysine ratio in weaned pigs challenged with enterotoxigenic Escherichia coli. Anim. Feed Sci. Technol., 227, 118-130. DOI:10.1016/j.anifeedsci.2017.03.004

Chen, Y. Li, D., Dai, Z., Piao, X., Wu, Z., Wang, B., Zhu, Y., Zeng, Z., 2014. L-methionine supplementation maintains the integrity and barrier function of the small-intestinal mucosa in post-weaning piglets. Amino Acids 46, 1131-1142. DOI: 10.1007/s00726-014-1675-5.

Christen, S., Peterhans, E., Stocker, R., 1990. Antioxidant activities of some tryptophan metabolites: possible implication for inflammatory diseases. Proc. Natl. Acad. Sci. US A 87, 2506-2510.

Corl, B., Odle, J., Niu, X., Moeser, A., Gatlin, L., Phillips, O., Blikslager, A.T., Rhoads, J.M., 2008. Arginine activates intestinal p70(S6k) and protein synthesis in piglet rotavirus enteritis. J. Nutr. 138, 24-29.

Curi, R., Lagranha, C., Doi, S., Sellitti, D., Procopio, J., Pithon-Curi, T., Corless, M., Newsholme, P.I., 2005. Molecular mechanisms of glutamine action. J. Cell. Physiol 204, 392-401. DOI: 10.1002/jcp.20339.

Davis, T.A., Fiorotto, M.L., Suryawan, A., 2015. Bolus vs. continuous feeding to optimize anabolism in neonates. Curr. Opin. Clin. Nutr. 18, 102-108. DOI: 10.1097/MCO.0000000000000128. 
de Ridder, K., Levesque, C.L. , Htoo, J.K. , de Lange, C.F.M., 2012. Immune system stimulation reduces the efficiency of tryptophan utilization for body protein deposition in growing pigs. J. Anim. Sci. 90, 34853491. DOI: 10.2527/jas.2011-4830.

Duan, J., Yin, J., Ren, W., Liu, T., Cui, Z., Huang, X., Wu, L., Kim, S.W., Liu, G., Wu, X., Wu, G., Li, T., Yin, Y., 2016. Dietary supplementation with L-glutamate and L-aspartate alleviates oxidative stress in weaned piglets challenged with hydrogen peroxide. Amino Acids 48, 53-64. DOI: 10.1007/s00726-015-2065-3.

Easter, R.A., Katz, R.S., Baker, D.H., 1974. Arginine: a dispensable amino acid for postpubertal growth and pregnancy of swine. J. Anim. Sci. 39, 1123-1128.

Escobar, J., Van Alstine, W.G., Baker, D.H., Johnson, R.W., 2004. Decreased protein accretion in pigs with viral and bacterial pneumonia is associated with increased myostatin expression in muscle. J. Nutr. 134, 30473053.

Fan, P., Liu, P., Song, P., Chen, X., Ma, X., 2017. Moderate dietary protein restriction alters the composition of gut microbiota and improves ileal barrier function in adult pig model. Sci. Rep. 7, 43412. DOI: $10.1038 /$ srep43412.

Frost, R.A., Lang, C.H., 2011. mTor signaling in skeletal muscle during sepsis and inflammation: Where does it all go wrong? Physiology 26, 83-96. DOI: 10.1152/physiol.00044.2010.

Garcia-Launay, F., van der Werf, H.M.G., Nguyen, T.T.H., LeTutour, L., Dourmad, J.Y., 2014. Evaluation of the environmental implications of the incorporation of feed-use aminoacids in pig production using Life Cycle Assessment. Liv. Sci. 161, 158-175. DOI: 10.1017/S1751731111001078.

Gloaguen, M., Le Floc'h, N., Corrent, E., Primot, Y., van Milgen, J., 2014. The use of free amino acids allows formulating very low crude protein diets for piglets. J. Anim. Sci. 92, 637-644. DOI: 10.2527/jas.20136514.

Goda, K., Hamane, Y., Kishimoto, R., Ogishi, Y., 1999. Radical scavenging properties of tryptophan metabolites. Estimation of their radical reactivity. Adv. Exp. Med. Biol. 467, 397-402.

Groschwitz, K., Hogan, S., 2009. Intestinal barrier function: molecular regulation and disease pathogenesis. J. Allergy Clin. Immunol. 124, 3-20. DOI: 10.1016/j.jaci.2009.05.038. 
Hamard, A., Sève, B., Le Floc'h, N., 2007. Intestinal development and growth performance of early-weaned piglets fed a low-threonine diet. Animal 1, 1134-1142. DOI: 10.1017/S175173110700 0560. DOI: 10.1017/S1751731107000560.

Haynes, T., Li, P., Li, X., Shimotori, K., Sato, H., Flynn, N., Wang, J., Knabe, D.A., Wu, G., 2009. L-Glutamine or L-alanyl-L-glutamine prevents oxidant- or endotoxin-induced death of neonatal enterocytes. Amino Acids 37, 131-142. DOI: 10.1007/s00726-009-0243-x.

He, L., Yang, H., Hou, Y., Li, T., Fang, J., Zhou, X., Yin, Y., Wu, L., Nyachoti, M., Wu, G., 2013. Effects of dietary L-lysine intake on the intestinal mucosa and expression of CAT genes in weaned piglets. Amino Acids 45, 383-391. DOI: 10.1007/s00726-013-1514-0.

He, Y., Deen, .J, Shurson, G.C., Wang, L., Chen, C., Keisler, D.H., Li, Y.Z., 2016. Identifying factors contributing to slow growth in pigs. J. Anim. Sci. 94, 2103-2116. DOI: 10.2527/jas.2015-0005.

Hou, Y.Q., Wu, G. 2017. Nutritionally nonessential amino acids: A misnomer in nutritional sciences. Adv. Nutr. 8, 137-139.

Hou, Y.Q., Wang, L., Yi, D., Wu, G., 2015a. N-acetylcysteine and intestinal health: a focus on mechanisms of its actions. Front. Biosci. 20, 872-891.

Hou, Y.Q., Yin, Y.L., Wu, G., 2015b. Dietary essentiality of "nutritionally nonessential amino acids" for animals and humans. Exp. Biol. Med. 240, 997-1007. DOI: 10.1177/1535370215587913.

Hou, Y.Q., Hu, S.D., Jia, S.C., Nawaratna, G., Che, D.S. Wang, F.L., Bazer, F.W., Wu, G., 2016a. Whole-body synthesis of L-homoarginine in pigs and rats supplemented with L-arginine. Amino Acids 48, 993-1001. DOI: 10.1007/s00726-015-2145-4.

Hou, Y.Q., Yao, K., Yin, Y.L., Wu, G., 2016b. Endogenous synthesis of amino acids limits growth, lactation and reproduction of animals. Adv. Nutr. 7, 331-342. DOI: 10.3945/an.115.010850.

Jahoor, F., Wykes, L., Del Rosario, M., Frazer, M, Reeds, P.J., 1999. Chronic protein undernutrition and an acute inflammatory stimulus elicit different protein kinetic responses in plasma but not in muscle of piglets. J. Nutr. 129, 693-699.

Jiao, N., Wu, Z., Ji, Y., Wang, B., Dai, Z., Wu, G., 2015. L-glutamate enhances barrier and antioxidative functions in intestinal porcine epithelial cells. J. Nutr. 145, 2258-2264. DOI: 10.3945/jn.115.217661. 
Jayaraman, B., Regassa, A., Htoo, J.K. and Nyachoti, C.M., 2017. Effects of dietary standardized ileal digestible tryptophan: lysine ratio on performance, plasma urea nitrogen, ileal histomorphology and immune responses in weaned pigs challenged with Escherichia coli K88. Liv. Sci. 203, 114-119. DOI: 10.1016/j.livsci.2017.07.014

Kalhan, S. C., Hanson, R. W., 2012. Resurgence of serine: an often neglected but indispensable amino Acid. J. Biol. Chem., 287: 19786-19791. DOI: 10.1074/jbc.R112.357194.

Kampman-van de Hoek, E. Sakkas, P., Gerrits, W.J., van den Borne, J.J., van der Peet-Schwering, C.M., Jansman, A.J., 2015. Induced lung inflammation and dietary protein supply affect nitrogen retention and amino acid metabolism in growing pigs. Br J. Nutr. 113, 414-425. DOI: 10.1017/S0007114514003821.

Kampman-van de Hoek, E., Jansman, A.J., van den Borne, J.J., van der Peet-Schwering, C.M., van BeersSchreurs, H., Gerrits, W.J., 2016. Dietary amino acid deficiency reduces the utilization of amino acids for growth in growing pigs after a period of poor health. J. Nutr. 146, 51-58. DOI: 10.3945/jn.115.216044.

Karinch, A.M., Pan, M., Lin, C.M., Strange, R., Souba, W.W., 2001. Glutamine metabolism in sepsis and infection. J. Nutr. 131, 2535S-2538S.

Kim, C.J., Kovacs-Nolan, J.A., Yang, C., Archbold, T., Fan, M.Z., Mine, Y., 2010. L-Tryptophan exhibits therapeutic function in a porcine model of dextran sodium sulfate (DSS)-induced colitis. J. Nutr. Biochem., 21, 468-475. DOI: 10.1016/j.jnutbio.2009.01.019.

Kim, S.W., McPherson, R.L., Wu, G., 2004. Dietary arginine supplementation enhances the growth of milkfed young pigs. J. Nutr. 134, 625-630.

Kim, S.W., Wu, G., 2009. Regulatory role for amino acids in mammary gland growth and milk synthesis. Amino Acids 37, 89-95. DOI: 10.1007/s00726-008-0151-5.

Kirchgessner, V.M., Rader, M.G., Roth-Maier, D.A., 1991. Influence of an oral arginine supplementation on lactation performance of sows. J. Anim. Physiol. Anim. Nutr. 66, 38-44.

Klasing, K.C., Johnstone,B.J., 1991. Monokines in growth and development. Poultry Sci. 70, 1781-1789.

Koopmans, S.J., Guzik A.C., van der Meulen, J., Dekker, R., Kogut, J., Kerr, B.J., Southern, L.L., 2006. Effects of supplemental L-tryptophan on serotonin, cortisol, intestinal integrity, and behavior in weanling piglets. J Anim Sci.84, 963-971. 
Lang, C. H., Frost, R.A., 2005. Endotoxin disrupts the leucine signaling pathway involving phosphorylation of mTOR, 4EBP1, and S6K1 in skeletal muscle. J. Cell. Physiol. 203, 144-155. DOI: 10.1002/jcp.20207.

Laspiur, J.P., Trottier, N.L., 2001. Effect of dietary arginine supplementation and environmental temperature on sow lactation performance. Livest. Prod. Sci. 70, 159-165.

Law, G.K., Bertolo, R.F., Adjiri-Awere, A., Pencharz, P.B., Ball, R.O., 2007. Adequate oral threonine is critical for mucin production and gut function in neonatal piglets. Am. J. Physiol. Gastrointest. Liver Physiol. 292, G1293-G12301. DOI: 10.1152/ajpgi.00221.2006.

Le Floc'h, N., Melchior, D., Obled, C., 2004. Modifications of protein and amino acid metabolism during inflammation and immune system activation. Livest. Prod. Sci. 87, 37-45.

Le Floc'h, N., Melchior, D., Seve, B., 2008. Dietary tryptophan helps to preserve tryptophan homeostasis in pigs suffering from lung inflammation. J. Anim. Sci. 86, 3473-3479. DOI: 10.2527/jas.2008-0999.

Le Floc'h, N., Matte, J.J., Melchior, D., van Milgen, J., Seve,B., 2010. A moderate inflammation caused by the deterioration of housing conditions modifies Trp metabolism but not Trp requirement for growth of post-weaned piglets. Animal 4, 1891-1898. DOI: 10.1017/S1751731110000236.

Le Floc'h, N., Otten, W, Merlot, E., 2011. Tryptophan metabolism, from nutrition to potential therapeutic applications. Amino Acids 41, 1195-1205. DOI: 10.1007/s00726-010-0752-7.

Le Floc'h, N., Simongiovanni, A., Corrent, E., Matte J.J., 2017. Comparison of growth and plasma tryptophan related metabolites in crossbred Piétrain and Duroc pigs. J. Anim. Sci. 95, 1606-1613. DOI:10.2527/jas.2016.1179

Li, D.F., Changting, X., Shiyan, Q., Jinhui, Z., Johnson, E.W., Thacker, P.A., 1999. Effects of dietary threonine on performance, plasma parameters and immune function of growing pigs. Anim. Feed Sci. Technol. 78, 179-188.

Li, H., Wan, H., Mercier, Y., Zhang, X., Wu, C., Wu, X., Tang, L., Che, L., Lin, Y., Xu, S., Tian, G., Wu, D., Tian, G., 2014. Changes in plasma amino acid profiles, growth performance and intestinal antioxidant capacity of piglets following increased consumption of methionine as its hydroxy analogue. $\mathrm{Br}$ J. Nutr. 112, 855-867. DOI: $10.1017 /$ S000711451400172X. 
Li, P., Yin, Y.L., Li, D.F., Kim, S.W., Wu, G., 2007. Amino acids and immune function. Br. J. Nutr. 98, 237-252. DOI: 10.1017/S000711450769936X.

Li, W., Sun, K., Ji, Y., Wu, Z., Wang, W., Dai, Z., Wu, G., 2016. Glycine regulates expression and distribution of claudin-7 and ZO-3 proteins in intestinal porcine epithelial cells. J. Nutr. 146, 964-969. DOI: 10.3945/jn.115.228312.

Lien, K.A., Sauer, W.C., Mosenthin, R., Souffrant, W.B., Dugan, M.E., 1997. Evaluation of the 15N-isotope dilution technique for determining the recovery of endogenous protein in ileal digestion of pigs: effect of dilution in the precursor pool for endogenous nitrogen secretion. J. Anim. Sci. 75, 148-158.

Litvak, N., Rakhshandeh, A., Htoo, J.K., de Lange, C.F.M., 2013. Immune system stimulation increases the optimal dietary methionine to methionine plus cysteine ratio in growing pigs. J. Anim. Sci. 91, 41884196. DOI: 10.2527/jas.2012-6160.

Lv, M. Yu, B., Mao, X.B., Zheng, P., He, J., Chen, D.W., 2012. Responses of growth performance and tryptophan metabolism to oxidative stress induced by diquat in weaned pigs. Animal 6, 928-934. DOI: $10.1017 /$ S1751731111002382.

Ma, X., Lin, Y., Jiang, Z., Zheng, C., Zhou, G., Yu, D., Cao, T., Wang, J., Chen, F., 2010. Dietary arginine supplementation enhances antioxidative capacity and improves meat quality of finishing pigs. Amino Acids 38, 95-102. DOI: 10.1007/s00726-008-0213-8.

Malmezat, T., Breuille, D., Pouyet, C., Mirand, P.P., Obled, C., 1998. Metabolism of cysteine is modified during the acute phase of sepsis in rats. J. Nutr. 128, 97-105.

Malmezat, T., Breuillé, D., Pouyet, C., Buffière, C., Denis, P., Mirand, P.P., Obled, C., 2000. Methionine transsulfuration is increased during sepsis in rats. Am. J. Physiol. Endocrinol. Metab. 279, E1391-1397.

Mao, X., Lai, X., Yu, B., He, J., Yu, J., Zheng, P., Tian, G., Zhang, K., Chen, D., 2014a. Effects of dietary threonine supplementation on immune challenge induced by swine Pseudorabies live vaccine in weaned pigs. Arch. Anim. Nutr. 68, 1-15. DOI: 10.1080/1745039X.2013.869988.

Mao, X., Lv, M., Yu, B., He, J., Zheng, P., Yu, J., Wang Q., Chen, D., 2014b. The effect of dietary tryptophan levels on oxidative stress of liver induced by diquat in weaned piglets. J. Anim. Sci. Biotechnol. 5, 20491891. DOI: 10.1186/2049-1891-5-49. DOI: 10.1186/2049-1891-5-49. 
Mateo, R.D., Wu, G., Bazer, F.W., Park, J.C., Shinzato, I., Kim, S.W., 2007. Dietary L-arginine supplementation enhances the reproductive performance of gilts. J. Nutr. 137, 652-656.

Mateo, R.D., Wu, G., Moon, H.K, Carroll, J.A., Kim, S.W., 2008. Effects of dietary arginine supplementation during gestation and lactation on the performance of lactating primiparous sows and nursing piglets. J. Anim. Sci. 86, 827-835. DOI: 10.2527/jas.2007-037.

Melchior, D., Seve, B., Le Floc'h, N., 2004. Chronic lung inflammation affects plasma amino acid concentrations in pigs. J. Anim. Sci. 82, 1091-1099.

Melchior, D., Meziere, N., Seve, B., Le Floc'h, N., 2005. Is tryptophan catabolism increased under indoleamine 2,3 dioxygenase activity during chronic lung inflammation in pigs? Reprod. Nutr. Dev. 45, 175-183.

Mondello, S., Galuppo, M., Mazzon, E., Domenico, I., Mondello, P., Carmela, A.,Cuzzocrea, S., 2010. Glutamine treatment attenuates the development of ischaemia/reperfusion injury of the gut. Eur. J. Pharmacol. 643, 304-315. DOI: 10.1016/j.ejphar.2010.06.044.

Moshage, H., 1997. Cytokines and the hepatic acute phase response. J. Pathol. 181, 257-266.

Munn, D.H., Zhou, M., Attwood, J.T., Bondarev, I., Conway, S.J., Marshall, B., Brown, C., Mellor, A.L., 1998. Prevention of allogeneic fetal rejection by tryptophan catabolism. Science 281, 1191-1193.

Munn, D.H., Mellor, L.A., 2013. Indoleamine 2,3 dioxygenase and metabolic control of immune responses. Trends Immunol. 34, 137-143. DOI: 10.1016/j.it.2012.10.001.

National Research Council (NRC), 2012. Nutrient Requirements of Swine, 11th rev. ed. Natl. Acad. Press, Washington, DC. DOI: 10.17226/13298.

Noth, R., Hasler, R., Stuber, E., Ellrichmann, M., Schafer, H., Geismann, C., Hampe, J., Bewig, B., Wedel, T., Böttner, M., Schreiber, S., Rosenstiel, P., Arlt, A., 2013. Oral glutamine supplementation improves intestinal permeability dysfunction in a murine acute graft-vs.-host disease model. Am. J. Physiol. Gastrointest. Liver Physiol. 304, G646-54. DOI: 10.1152/ajpgi.00246.2012.

Obled, C., Papet, I.,Breuillé, D., 2002. Metabolic bases of amino acid requirements in acute diseases. Curr. Opin. Clin. Nutr. Metab. Care 5, 189-197. 
Pastorelli, H., Van Milgen, J., Lovatto, P., Montagne, L., 2012. Meta-analysis of feed intake and growth responses of growing pigs after a sanitary challenge. Animal 6, 952-961. DOI: 10.1017/S175173111100228X.

Peng, Y., Yu, K., Mu, C., Hang, S., Che, L., Zhu, W., 2017. Progressive response of large intestinal bacterial community and fermentation to the stepwise decrease of dietary crude protein level in growing pigs. Appl. Microbiol. Biotechnol. 101, 5415-5426. DOI: 10.1007/s00253-017-8285-6.

Pi, D., Liu, Y., Shi, H., Li, S., Odle, J., Lin, X., Zhu, H., Chen, F., Hou, Y., Leng, W., 2014. Dietary supplementation of aspartate enhances intestinal integrity and energy status in weanling piglets after lipopolysaccharide challenge. J. Nutr. Biochem 25, 456-462. DOI: 10.1016/j.jnutbio.2013.12.006.

Popov, A., Schultze, J.L., 2008. IDO-expressing regulatory dendritic cells in cancer and chronic infection. J. Mol. Med. 86, 145-160. DOI: 10.1007/s00109-007-0262-6.

Rakhshandeh, A., de Lange, C.F.M., 2010. Immune system stimulation increases reduced glutathione synthesis rate in growing pigs. in: Energy and Protein Metabolism and Nutrition (Ed. G. Matteo Crovetto). EAAP publication No. 127. Wageningen Academic Publishers, Wageningen, The Netherlands. pp. 501502.

Rakhshandeh, A., De Ridder, K., Htoo, J.K., de Lange, C. F.M., 2010. Immune system stimulation alters plasma cysteine kinetics in growing pigs. In: Matteo Crovetto, G.(Eds.) Energy and Protein Metabolism and Nutrition. EAAP publication No. 127. Wageningen Academic Publishers, Wageningen, The Netherlands. pp. 509-510. DOI: 10.3920/978-90-8686-709-7.

Rakhshandeh, A., Htoo, J. K., Karrow, N. Miller, S. P., de Lange, C. F.M., 2014. Impact of immune system stimulation on the ileal nutrient digestibility and utilisation of methionine plus cysteine intake for wholebody protein deposition in growing pigs. Br J. Nutr. 111, 101-110. DOI: 10.1017/S0007114513001955.

Reeds, P.J., Fjeld, C.R., Jahoor, F., 1994. Do the differences between the amino acid compositions of acutephase and muscle proteins have a bearing on nitrogen loss in traumatic states? J. Nutr. 124, 906-910.

Rémond, D., Buffière, C., Godin, J.P., Mirand, P.P., Obled, C., Papet, I., Dardevet, D., Williamson, G., Breuille, D., Faure, M., 2009. Intestinal inflammation increases gastrointestinal threonine uptake and mucin synthesis in enterally fed minipigs. J. Nutr. 139, 720-726. DOI: 10.3945/jn.108.101675. 
Rémond, D., Buffière, C., Pouyet, C., Papet, I., Dardevet, D., Savary-Auzeloux, I., Williamson, G., Faure, M., Breuillé, D., 2011. Cysteine fluxes across the portal-drained viscera of enterally fed minipigs: effect of an acute intestinal inflammation. Amino Acids 40, 543-552. DOI: 10.1007/s00726-010-0672-6.

Rezaei, R., Knabe, D.A., Tekwe, C.D., Dahanayaka, S., Ficken, M.D., Fielder, S.E., Eide, S.J., Lovering, S.L., Wu, G., 2013. Dietary supplementation with monosodium glutamate is safe and improves growth performance in postweaning pigs. Amino Acids 44, 911-923. DOI: 10.1007/s00726-012-1420-x.

Ren, M., Liu, X., Wang, X., Zhang, G., Qiao, S., Zeng, X., 2014. Increased levels of standardized ileal digestible threonine attenuate intestinal damage and immune responses in Escherichia coli K88+ challenged weaned piglets. Anim. Feed. Sci. Technol. 195, 67-75. DOI: 10.1016/j.anifeedsci.2014.05.013

Rhoads, J., Wu, G., 2009. Glutamine, arginine, and leucine signaling in the intestine. Amino Acids 37, 111122. DOI: $10.1007 / \mathrm{s} 00726-008-0225-4$.

Rhoads, J., Argenzio, R., Chen, W., Rippe, R., Westwick, J., Cox, A., Berschneider, H.M., Brenner, D.A., 1997. L-glutamine stimulates intestinal cell proliferation and activates mitogen-activated protein kinases. Am. J. Physiol. 272, G943-953.

Rojo-Gimeno, C., Postma, M., Dewulf, J., Hogeveen, H., Lauwers, L., Wauters, E., 2016. Farm-economic analysis of reducing antimicrobial use whilst adopting improved management strategies on farrow-tofinish pig farms. Prev. Vet. Med. 129, 74-87. DOI:org/10.1016/j.prevetmed.2016.05.001

Sharma, M.D., Baban, B., Chandler, P., Hou, D.Y., Singh, N., Yagita, H., Azuma,M., Blazar, B.R., Mellor,A.L., Munn, D.H., 2007. Plasmacytoid dendritic cells from mouse tumor-draining lymph nodes directly activate mature Tregs via indoleamine 2,3-dioxygenase. J. Clin. Invest. 117, 2570-2582. DOI: $10.1172 / \mathrm{JCI} 31911$.

Sakiyama, T., Musch, M., Ropeleski, M., Tsubouchi, H., Chang, E., 2009. Glutamine increases autophagy under basal and stressed conditions in intestinal epithelial cells. Gastroenterol. 136, 924-932. DOI: 10.1053/j.gastro.2008.12.002.

Soler, L., Miller, I., Nöbauer, K., Carpentier, S., Niewold, T., 2015. Identification of the major regenerative III protein (RegIII) in the porcine intestinal mucosa as RegIIly, not Regllla. Vet. Immunol. Immunopathol. 167, 51-56. DOI: 10.1016/j.vetimm.2015.07.006. 
Tan, B.E., Li, X.G., Kong, X.G., Huang, R.L., Ruan, Z., Yao, K., Deng, Z.Y., Xie, M.Y., Shinzato, I., Yin, Y.L., Wu, G., 2009a. Dietary L-arginine supplementation enhances the immune status in early-weaned piglets. Amino Acids 37, 323-331. DOI: 10.1007/s00726-008-0155-1.

Tan, B.E., Yin, Y.L., Liu, Z., Li, X.G., Xu, H., Kong, X., Huang, R.L., Tang, W.J., Shinzato, I., Smith, S.B., Wu, G., 2009b. Dietary L-arginine supplementation increases muscle gain and reduces body fat mass in growingfinishing pigs. Amino Acids 37, 169-175. DOI: 10.1007/s00726-008-0148-0.

Tan, B.E., Yin, Y., Kong, X., Li, P., Li, X., Gao, H., Li, X.G., Huang, R.L., Wu, G., 2010. L-Arginine stimulates proliferation and prevents endotoxin-induced death of intestinal cells. Amino Acids 38, 1227-1235. DOI: 10.1007/s00726-009-0334-8.

Tenenhouse, H., Deutsch, H., 1966. Some physical-chemical properties of chicken $\gamma$-globulins and their pepsin and papain digestion products. Immunochemistry 3, 11-20.

Trevisi, P., Melchior, D., Mazzoni, M., Casini, L., De Filippi, S., Minieri, L., Lalatta Costerbosa, G., Bosi, P., 2009. A tryptophan-enriched diet improves feed intake and growth performance of susceptible weanling pigs orally challenged with Escherichia coli K88. J. Anim. Sci. 87, 148-156. DOI: 10.2527/jas.2007-0732.

Trevisi, P., Corrent, E., Mazzoni, M., Messori, S., Priori, D., Gherpelli, Y., Simongiovanni, A., Bosi, P., 2015a. Effect of added dietary threonine on growth performance, health, immunity and gastrointestinal function of weaning pigs with differing genetic susceptibility to Escherichia coli infection and challenged with E. coli K88ac. J. Anim. Physiol. Anim. Nutr. 99, 511-520. DOI: 10.1111/jpn.12216.

Trevisi, P., Ribani, A., Colombo, M., Utzeri, V.J., Bosi, P., Fontanesi, L., 2015b. A first nutrigenomics trial in pigs identifies a DNA polymorphism affecting kynurenine metabolites after tryptophan addition and challenge with enteroxigenic E. coli F4. In: Book of Abstracts. $13^{\text {th }}$ Digestive Physiology in Pigs Symposium, May 19-21, 2015,Kliczków, Poland.pp. 85, Poster 1.19

Trevisi, P., Priori, D., Jansman, A. J., Luise, D., Koopmans, S. J., Hynönen, U., Palva, A., van der Meulen, J., Bosi, P., 2018. Molecular networks affected by neonatal microbial colonization in porcine jejunum, luminally perfused with enterotoxigenic Escherichia coli, F4ac fimbria or Lactobacillus amylovorus. PloS one, 13, e0202160. DOI: 10.1371/journal.pone.0202160. 
van Heugten, E., Spears, J.W., Coffey, M.T., 1994. The effect of dietary protein on performance and immune response in weanling pigs subjected to an inflammatory challenge. J. Anim. Sci. 72, 2661-2669.

Wang, J.J., Chen, L.X., Li, P., Li, X.L., Zhou, H.J., Wang, F.L., Li, D.F., Yin, Y.L., Wu, G. 2008. Gene expression is altered in piglet small intestine by weaning and dietary glutamine supplementation. J. Nutr. 138:10251032.

Wang, H., Zhang, C., Wu, G., Sun, Y., Wang, B., He, B., Dai, Z., Wu. Z., 2015. Glutamine enhances tight junction protein expression and modulates corticotropin-releasing factor signaling in the jejunum of weanling piglets. J. Nutr. 145, 25-31. DOI: 10.3945/jn.114.202515.

Wang, H., Liu, Y., Shi, H., Wang, X., Zhu, H., Pi, D., Leng, W., Li, S., 2016. Aspartate attenuates intestinal injury and inhibits TLR4 and NODs/NF-kappaB and p38 signaling in weaned pigs after LPS challenge. Eur J. Nutr. DOI: $10.1007 / \mathrm{s} 00394-016-1189-x$

Wang, W., Qiao, S., Li, D., 2009. Amino acids and gut function. Amino Acids 37, 105-110. DOI: 10.1007/s00726-008-0152-4.

Wang, W., Wu, Z.L. Dai, Z.L., Yang, Y.,Wang, J.J., Wu, G., 2013. Glycine metabolism in animals and humans: implications for nutrition and health. Amino Acids 45, 463-477. DOI: 10.1007/s00726-013-1493-1

Wang, W., Wu, Z., Lin, G., Hu, S., Wang, B., Dai, Z., Wu, G., 2014a. Glycine stimulates protein synthesis and inhibits oxidative stress in pig small intestinal epithelial cells. J. Nutr. 144, 1540-1548. DOI: 10.3945/jn.114.194001.

Wang, W., Dai, Z.L., Wu, Z.L., Lin, G., Jia, S.C., Hu, S.D., Dahanayaka, S., Wu, G., 2014b. Glycine is a nutritionally essential amino acid for maximal growth of milk-fed young pigs. Amino Acids 46, 2037-2045. DOI: 10.1007/s00726-014-1758-3.

Wang, X., Qiao, S.Y., Liu, M., Ma, Y.X., 2006. Effects of graded levels of true ileal digestible threonine on performance, serum parameters and immune function of 10-25 kg pigs. Anim. Feed Sci. Technol. 129, 264-278. DOI: 10.1016/j.anifeedsci.2006.01.003.

Wilson, F.A., Suryawan, A., Orellana, R.A., Kimball, S.R., Gazzaneo, M.C., Nguyen, H.V., Fiorotto, M.L., Davis, T.A., 2009. Feeding rapidly stimulates protein synthesis in skeletal muscle of neonatal pigs by enhancing translation initiation. J.Nutr. 139, 1873-1880. DOI: 10.3945/jn.109.106781. 
Wirthgen, E., Tuchscherer, M., Otten, W., Domanska, G., Wollenhaupt, K., Tuchscherer, A., Kanitz, E., 2014. Activation of indoleamine 2,3-dioxygenase by LPS in a porcine model. Innate Immun. 20, 30-39. DOI: $10.1177 / 1753425913481252$.

Wu, G., 1997. Synthesis of citrulline and arginine from proline in enterocytes of postnatal pigs. Am. J. Physiol. 272, G1382-G1390.

Wu, G., 1998. Intestinal mucosal amino acid catabolism. J. Nutr. 128, 1249-1252.

Wu, G., 2010. Functional amino acids in growth, reproduction and health. Adv. Nutr. 1, 31-37. DOI: 10.3945/an.110.1008.

Wu, G., 2013. Amino acids: biochemistry and nutrition. CRC Press: Boca Raton, Florida.

Wu, G., 2014. Dietary requirements of synthesizable amino acids by animals: A paradigm shift in protein nutrition. J. Anim. Sci. Biotechnol. 5, 34. DOI: 10.1186/2049-1891-5-34.

Wu, G., 2018. Principles of Animal Nutrition. CRC Press: Boca Raton, Florida.

Wu, G., Knabe, D.A., 1994. Free and protein-bound amino acids in sow's colostrums and milk. J. Nutr. 124, 415-424.

Wu, G., Morris, S.M., 1998. Arginine metabolism: nitric oxide and beyond. Biochem. J. 336, 1-17.

Wu, G., Meininger, C.J. 2009. Nitric oxide and vascular insulin resistance. BioFactors 35, 21-27.Wu, G., Borbolla, A.G., Knabe, D.A., 1994a. The uptake of glutamine and release of arginine, citrulline and proline by the small intestine of developing pigs. J. Nutr. 124, 2437-2444.

Wu, G., Knabe, D.A., Flynn, N.E., 1994b. Synthesis of citrulline from glutamine in pig enterocytes. Biochem. J. $299,115-121$.

Wu, G., Knabe, D.A., Flynn, N.E., Yan, W., Flynn, S.P., 1996a. Arginine degradation in developing porcine enterocytes. Am. J. Physiol. 271, G913-G919.

Wu, G., Meier, S.A., Knabe, D.A. 1996b. Dietary glutamine supplementation prevents jejunal atrophy in weaned pigs. J. Nutr. 126, 2578-2584.Wu, G., Fang, Y.Z., Yang, S., Lupton, J.R., Turner, N.D., 2004 a. Glutathione metabolism and its implications for health. J. Nutr. 134, 489-492.

Wu, G., Knabe, D.A., Kim, S.W., 2004b. Arginine nutrition in neonatal pigs. J. Nutr. 134, 2783S-2390S. 
Wu, G., Bazer, F.W., Davis, T.A., Jaeger, L.A., Johnson, G.A., Kim, S.W., Knabe, D.A., Meininger, C.J., Spencer, T.E., Yin, Y.L., 2007. Important roles for the arginine family of amino acids in swine nutrition and production. Livest. Sci. 112, 8-22. DOI: 10.1016/j.livsci.2007.07.003.

Wu, G., Bazer, F.W., Burghardt, R.C., Johnson, G.A., Kim, S.W., Knabe, D.A., Li, P., Li, X.K., McKnight, J.R., Satterfield, M.C., Spencer, T.E., 2011. Proline and hydroxyproline metabolism: implications for animal and human nutrition. Amino Acids 40, 1053-1063. DOI: 10.1007/s00726-010-0715-z.

Wu, G., Bazer, F.W., Satterfield, M.C., Li, X., Wang, X., Johnson, G.A., Burghardt, R.C., Dai, Z.L., Wang, J.J., Wu, Z.L.,2013a. Impacts of arginine nutrition on embryonic and fetal development in mammals. Amino Acids 45, 241-256. DOI: 10.1007/s00726-013-1515-z.

Wu, G., Wu, Z., Dai, Z., Yang, Y., Wang, W., Liu, C., Wang, B., Wang, J., Yin, Y., 2013b. Dietary requirements of "nutritionally non-essential amino acids" by animals and humans. Amino Acids 44, 1107-1113. DOI: 10.1007/s00726-012-1444-2.

Wu, G., Bazer, F.W., Dai, Z., Li, D., Wang, J., Wu, Z.L., 2014a. Amino acid nutrition in animals: protein synthesis and beyond. Annu. Rev. Anim. Biosci. 2, 387-417. DOI: 10.1146/annurev-animal-022513-114113.

Wu, G., Fanzo, J., Miller, D.D., Pingali, P., Post, M., Steiner, J.L., Thalacker-Mercer, A.E., 2014b. Production and supply of high-quality food protein for human consumption: sustainability, challenges and innovations. Ann. N.Y. Acad. Sci. 1321, 1-19. DOI: 10.1111/nyas.12500.

Wu, G., Bazer, F.W., Cross, H.R., 2014c. Land-based production of animal protein: impacts, efficiency, and sustainability. Ann. N.Y. Acad. Sci. 1328, 18-28. DOI: 10.1111/nyas.12566.

Wu, X., Z. Ruan, Z., Gao, Y., Yin, Y., Zhou, X., Wang, L., Geng, M.M., Hou, Y.Q., Wu, G., 2010. Dietary supplementation with L-arginine or N-carbamylglutamate enhances intestinal growth and heat shock protein-70 expression in weanling pigs fed a corn- and soybean meal-based diet. Amino Acids 39, 831839. DOI: 10.1007/s00726-010-0538-y.

Xi, P., Jiang, Z., Dai, Z., Li, X., Yao, K., Zheng, C., Lin, Y., Wang, J., Wu, G., 2012. Regulation of protein turnover by L-glutamine in porcine intestinal epithelial cells. J. Nutr. Biochem 23, 1012-1017. DOI: 10.1016/j.jnutbio.2011.05.009. 
Xu, C.C., Yang, S.F., Zhu, L.H., Cai, X., Sheng, Y.S., Zhu, S.W., Xu, J.X., 2014. Regulation of N-acetyl cysteine on gut redox status and major microbiota in weaned piglets. J. Anim. Sci. 92, 1504-1511. DOI: 10.2527/jas.2013-6755.

Yang, X.F., Jiang, Z.Y., Gong, Y.L., Zheng, C.T., Hu, Y.J., Wang, L., Huang, L., Ma, X.Y., 2016. Supplementation of pre-weaning diet with L-arginine has carry-over effect to improve intestinal development in young piglets. Can J. Anim. Sci. 96, 52-59. DOI: 10.1139/cjas-2015-0043.

Yen, J.T., Kerr, B.J., Easter, R.A., Parkhurst, A.M., 2004. Difference in rates of net portal absorption between crystalline and protein-bound lysine and threonine in growing pigs fed once daily. Journal of animal science $82,1079-1090$.

Yi, G., Carroll, J., Allee, G., Gaines, A., Kendall, D., Usry, J., Toride, Y., Izuru, S., 2005. Effect of glutamine and spray-dried plasma on growth performance, small intestinal morphology, and immune responses of Escherichia coli K88+-challenged weaned pigs. J. Anim. Sci. 83, 634-643.

Yin, J., Liu, M., Ren, W., Duan, J., Yang, G., Zhao, Y., Fang, R., Chen, L., Li, T., Yin, Y., 2015. Effects of dietary supplementation with glutamate and aspartate on diquat-induced oxidative stress in piglets. PLoS One 10, e0122893. DOI: 10.1371/journal.pone.0122893

Yoo, S.S., Field, C.J., McBurney, M.I., 1997. Glutamine supplementation maintains intramuscular glutamine concentrations and normalizes lymphocyte function in infected early weaned pigs. J. Nutr. 127, 22532259.

Zhang, B., Che, L.Q., Lin, Y., Zhuo, Y., Fang, Z.F., Xu, S.Y., Song, J., Wang, Y.S., Liu, Y., Wang, P., Wu, D., 2014. Effect of dietary N-carbamylglutamate levels on reproductive performance of gilts. Reprod. Domest. Anim. 49, 740-745. DOI: 10.1111/rda.12358.

Zheng, P., Yu, B., He, J., Tian, G., Luo, Y., Mao, X., Zhang, K., Che, L., Chen, D., 2013. Protective effects of dietary arginine supplementation against oxidative stress in weaned piglets. Br J. Nutr. 109, 2253-2260. DOI: 10.1017/S0007114512004321.

Zhou, X., Dong, L., Yang, B., He, Z., Chen, Y., Deng, T., Huang, B., Lan, C., 2015. Preinduction of heat shock protein 70 protects mice against post-infection irritable bowel syndrome via NF-kB and NOS/NO signaling pathways. Amino Acids 47, 2635-2645. DOI: 10.1007/s00726-015-2056-4. 
905 Zhu, H., Liu, Y., Xie, X., Huang, J., Hou, Y., 2013. Effect of L-arginine on intestinal mucosal immune barrier 906 function in weaned pigs after Escherichia coli LPS challenge. Innate immun 19, 242-252. DOI: 907 $10.1177 / 1753425912456223$.

908 
Table 1 Calculation of the most abundant amino acids in some relevant defense proteins secreted by the gut

\begin{tabular}{lc}
\hline Proteins & $\begin{array}{c}\text { The most represented } \mathrm{AA}^{1} \\
\text { Percentage } \\
\text { of total AA } \\
\text { number }^{1}\end{array}$ \\
\hline
\end{tabular}

\section{- Mucins}

Mucin 1 (more expressed in stomach)

Mucin 13 (more expressed in jejunum)

Asn

Mucin 20 (more expressed in colon)

Thr

$$
\text { - Immunoglobulins }
$$

IgA constant chain (Human)

Thr

9.6

IgM constant chain (Human)

Thr

Joining chain of Multimeric IgA And IgM

Thr

- Defense and antibacterial, lectins

Regenerating Family Member 3 Gamma

Ser

LY6/PLAUR Domain Containing 8

Thr

Ser

Lysozyme

Leu

10.1

Haptoglobin

Val

Alkaline phosphatase, intestinal

Arg / Leu

9.9 each

${ }^{1}$ The relative abundance of amino acids in a protein was calculated from the counting of each amino acid and of the total of amino acids encoded for by the gene's DNA sequence reported in Ensemble data base for pigs (or for human, when the sequence was not available). The second most abundant amino acid is in italics. Thr = threonine; Ser = serine; Asn = asparagine; Leu = leucine; Val = valine; $\operatorname{Arg}=$ arginine 
915 Fig. 1. Figure 1. Impacts of health disturbances on average daily feed intake (ADFI) and average daily 916 growth (ADG) in \% of the value for control healthy pigs (adapted from Pastorelli et al. 2012). The symbols

$917 *$ and ** indicate that the impacts of health disturbances differed for ADG and ADFI at $P<0.05$ and $P<0.01$, 918 respectively.

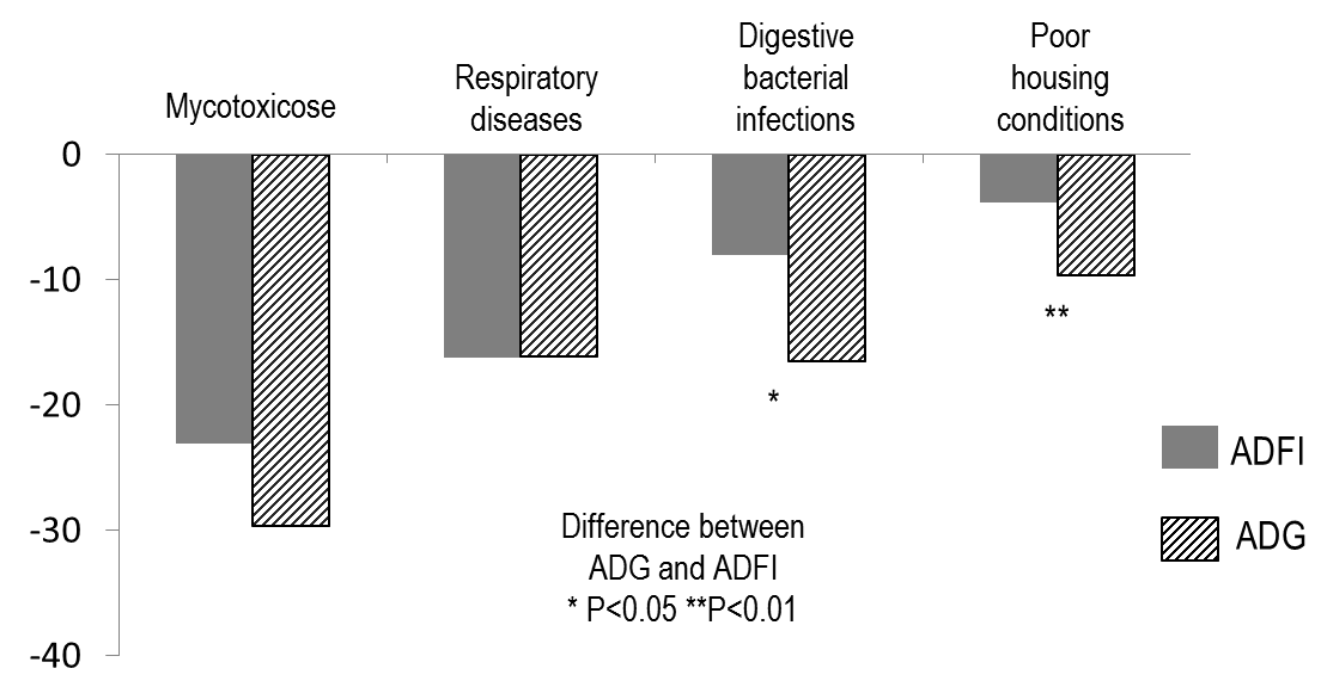

Average Feed Intake and mean growth response, \% Control

Figure 2. Mucosal barrier function and the structure of intestinal tight junctions (TJ). The intestinal epithelium provides a physical barrier to luminal bacteria, toxins, and antigens. The mucosal barrier is structured by different barrier components, including the TJ. The TJ structure is formed by membrane proteins such as occludin, members of the claudin family, and zonula occludens proteins ZO-1 and ZO-2. TJs regulate the paracellular passages of nutrients (e.g., amino acids) between adjacent cells, and their uptake into the blood stream. Any TJ barrier impairment allows for the passage of noxious molecules, which can induce the excessive activation of mucosal immune cells and inflammation. Therefore, intestinal mucosal barrier defects are associated with the initiation and development of various intestinal and systemic diseases. Dietary and circulating amino acids contribute to anti-inflammatory response in the body. 


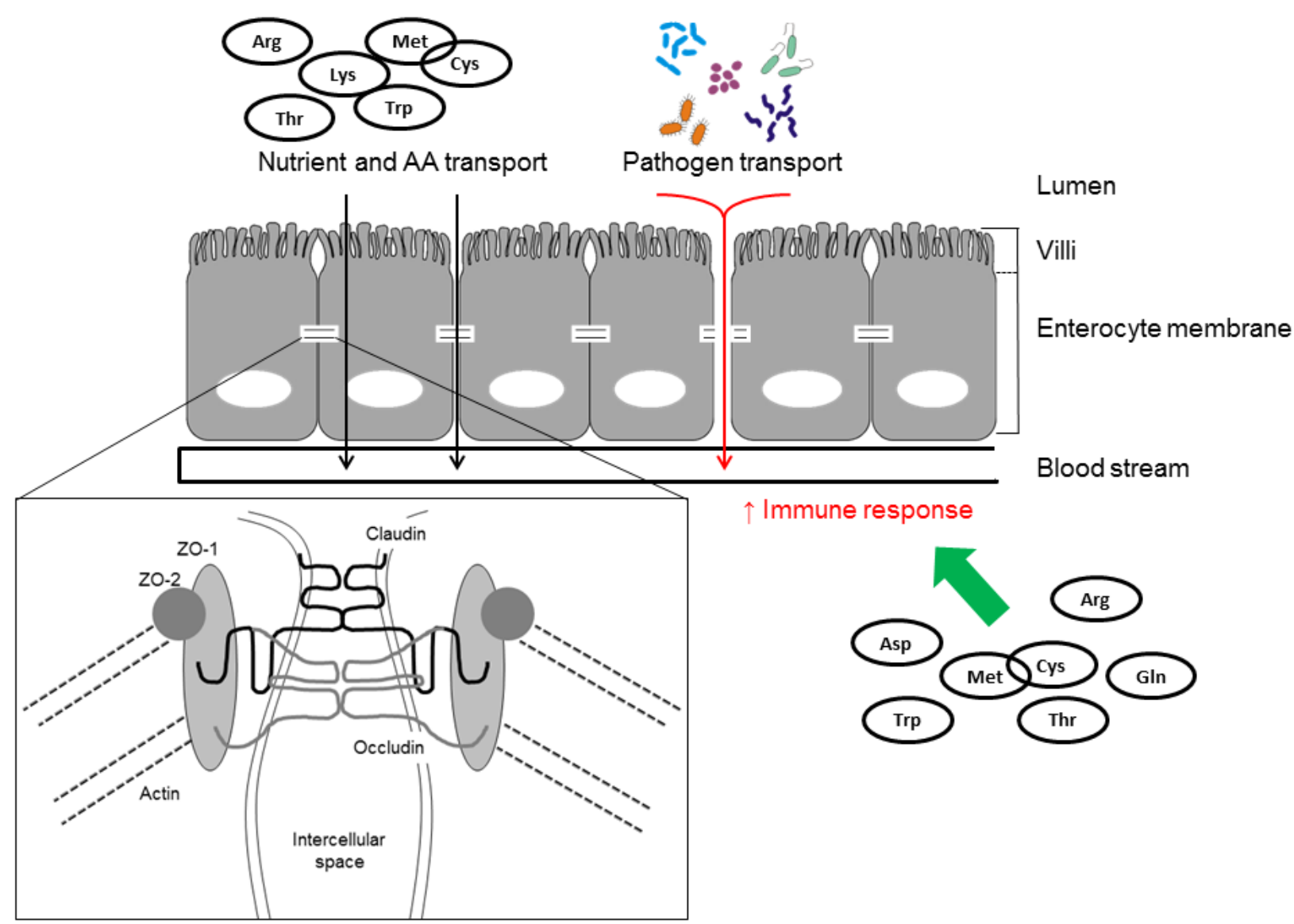

Nutrient and AA transport

Figure 3. Metabolism of the arginine-family of amino acids in the small intestine and liver of post-weaning,

933 growing pigs under fed conditions. Dietary protein is hydrolyzed in the lumen of the small intestine to release L-arginine (Arg), L-glutamine (Gln), L-glutamate (Glu), L-proline and other amino acids. Almost all Glu (95-97\%) and Asp (95\%), most GIn (70\%), 40\% Pro, and 40\% Arg in the lumen are metabolized by the small intestine, primarily in enterocytes and by bacteria) (Hou et al., 2016b). Within enterocytes, L-citrulline (Cit) is synthesized from Gln, Glu and Pro. These cells convert a small percentage of the Cit (10\%) into Arg and release $90 \%$ of the Cit, while hydrolyzing Arg into L-ornithine (Orn) through the action of arginase (Wu 1997). Arg and GIn inhibit the expression of toll-like receptor-4 (TLR-4) and nuclear factor kappa-lightchain-enhancer of activated B cells (NFkB) in response to inflammation (Hou et al. 2015a). The liver receives little Glu and Asp and a relatively small amount of Gln from the portal vein, and does not take up Cit. In multiple tissues of pigs, Cit is effectively converted into Arg, which is metabolized to ornithine, proline, glutamate and glutamine. The sign (-) denotes inhibition of gene expression in response to 944 inflammation. 


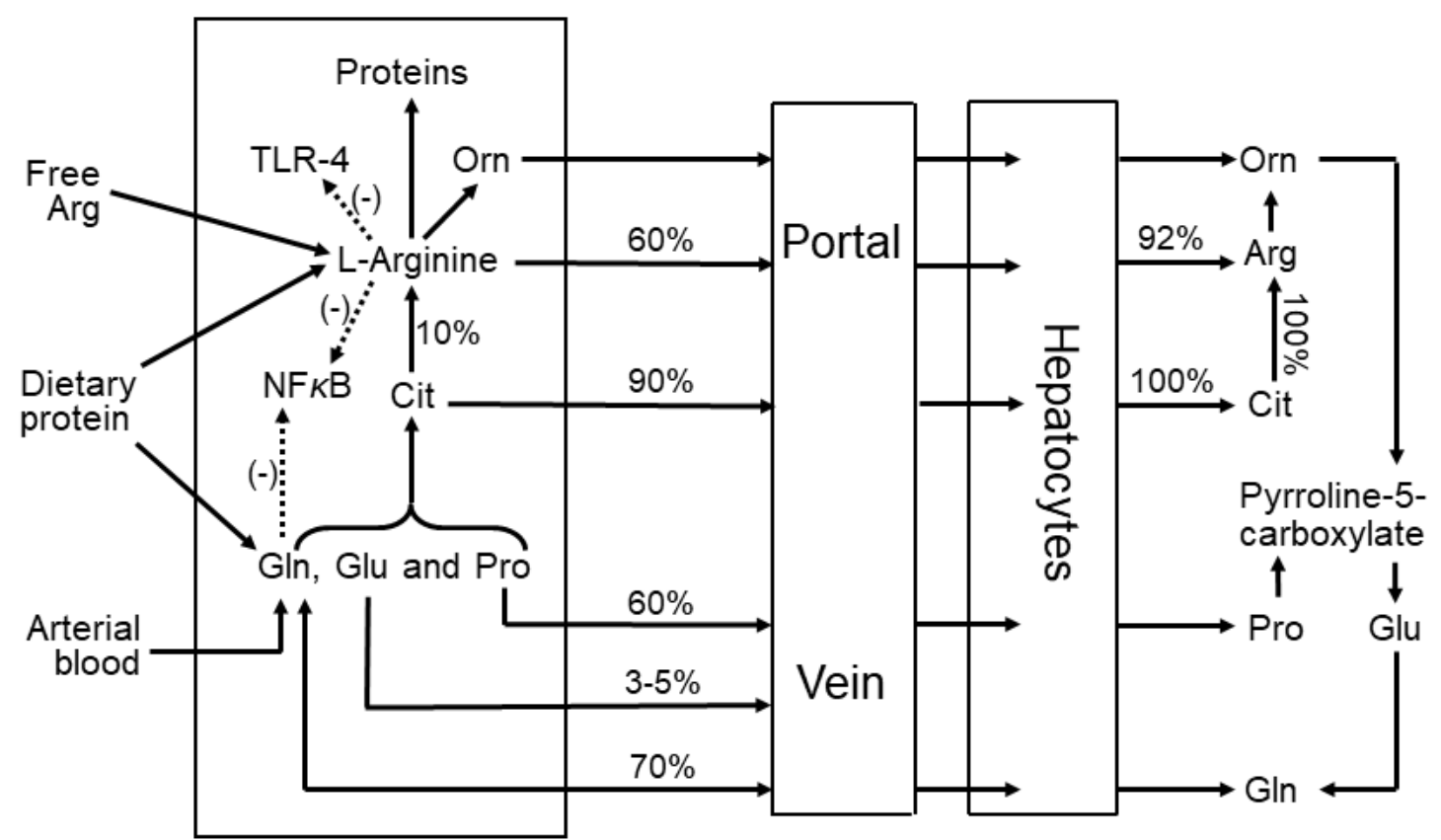

Enterocytes 